\title{
From the home to the clinic: The next chapter in Bangladesh's family planning success story rural sites
}

Linda Bates

Md. Khairul Islam

Sidney Ruth Schuler

Md. Alauddinn

Follow this and additional works at: https://knowledgecommons.popcouncil.org/departments_sbsr-rh

Part of the Demography, Population, and Ecology Commons, Health Services Research Commons, and the International Public Health Commons

How does access to this work benefit you? Let us know!

\section{Recommended Citation}

Bates, Linda, Md. Khairul Islam, Sidney Ruth Schuler, and Md. Alauddinn. 2000. "From the home to the clinic: The next chapter in Bangladesh's family planning success story rural sites," FRONTIERS Final Report. Washington, DC: Population Council. 
From the Home to the Clinic:

The Next Chapter in Bangladesh's

Family Planning Success Story

Rural Sites

\author{
Lisa Bates \\ Md Khairul Islam \\ Sidney Ruth Schuler \\ Md Alauddin
}

Revised November 2000

This small grant study was funded by the UNITED STATES AGENCY FOR

INTERNATIONAL DEVELOPMENT (USAID) under the terms of Cooperative Agreement number HRN-A-00-98-00012-00 for the Frontiers in Reproductive Health Program. This report is based on data collected by: Shefali Akter, Shamsul Huda Badal, Khurshida Begum, Mahbuba Hoque, Rasheda Khan, Rabeya Begum, and Tofazzal Hossain Monju, with support from Nabeel Ashraf Ali. Catherine Spaur and Sarah Martin contributed to the data analysis. The opinions expressed herein are those of the authors and do not necessarily reflect the view of USAID. 


\section{SUMMARY}

Bangladesh is one of many countries struggling to narrow the gap between policy and implementation of the expanded approach to reproductive health agreed to at the International Conference on Population and Development (ICPD). Many of the ICPD goals are embodied in the government's Health and Population Sector Strategy, and a number of USAID-supported NGOs are moving ahead to implement these changes. In line with government and donor priorities of the past, these NGOs previously had programs focusing on door-to-door family planning. Now that they have adopted the government's ESP approach, the NGOs have discontinued door-to-door contraceptive distribution. Services are being offered through clinics and satellite clinics, with village depots available for re-supplying contraceptives in rural areas. The NGOs are employing a variety of measures to improve the quality of services, to make the services more responsive to clients, and to increase their sustainability. The new NGO program is important as a test case of the new strategies because of both the nature of the changes made, and the speed with which they have been introduced. The findings from this study strongly support the policy changes reflected in the government's integrated, clinic-focused approach and the new USAID NGO program. Clients and communities are responding favorably to many aspects of the new model, and there do not seem to be intractable social barriers to service utilization.

\section{Demand and Access}

Many of the assumptions behind the changes had not been systematically proven, and some were controversial - for example, the assumption that demand for family planning is not too "fragile" to withstand the withdrawal of home-supply and that norms related to purdah will not prevent women from utilizing services outside the home. Findings from the rural areas in this study confirm quite clearly, however, that men and women are strongly committed to fertility control, and women are for the most part no longer socially constrained from leaving the home to obtain family planning and/or use health services. Access to the NGO services has improved over time, but the outreach efforts of the NGOs remain important, and the findings confirm that people are very appreciative of the information that is provided, particularly that which goes beyond the traditional focus on family planning.

- It will be important that NGOs continue to provide information and support so that the strong existing demand for services and the loosening restrictions on women's mobility translate into widespread service utilization.

- There is a need to strengthen the coverage of these outreach activities (male attendance is particularly low), and the NGOs need to sustain their focus on more than family planning issues.

- Outreach efforts to homes may be important to ensure that certain types of individuals and groups are not excluded from the new services but the NGOs need to ensure that such strategies are used selectively and do not inadvertently or needlessly discourage women from coming out of the home to access clinics. 
Men were often instrumental in facilitating the transition from door-to-door services. The lingering reluctance to be involved that remains among men appears to reflect their historic marginalization from public health and family planning programs as much as, or more so, than entrenched gender roles.

- The NGOs' outreach efforts to men are one promising vehicle for promoting normative change through messages about men's important roles in ensuring access to family planning, clinical services, and information, and should be strengthened.

The depot holders deployed by the NGOs have been very instrumental in smoothing the transition to the new program and they remain an important resource for clients and providers alike.

- It is important that depot holders are not overburdened with responsibilities they do not have the time or skills (or incentives) to manage. More emphasis could be placed on the role of the Community Mobilizer in disseminating information about the clinics and services available.

\section{Quality of care}

The findings also indicate that the NGOs have succeeded in understanding and incorporating many aspects of quality that are important to clients. People appreciate access to more comprehensive, higher quality family planning services, the improved physical environment of the clinics and, especially, the interpersonal aspects of the new NGO services. Respondents were overwhelmingly positive about the behavior of the NGO service providers - they appreciated being listened to and treated with kindness and respect. This was the aspect of the NGO services that was most consistently and earnestly praised.

Some clients commented that the staff's good behavior towards them was intended to attract them - that they had to be nice in order to build up a clientele (the assumption probably being that the clinics would have to close down and they would lose their jobs if they failed to attract clients). This perception may signal two things: one, that the NGOs seem to be succeeding in institutionalizing important aspects of quality at the clinics and thereby making them more reliably accessible (rather than based on personal relationships with individual providers); and two, that an emerging "consumer awareness" may be developing with regard to the use of health care facilities that, in the long run, could bring about better quality of care by forcing providers to compete for clients as the number of health care options available in rural as well as urban areas increases.

- The NGOs can contribute to these potentially positive trends by continuing to communicate to their staff the importance of quality and the idea that their viability will depend on their ability to respond to clients' priorities, and by encouraging staff to convey the same concepts to clients.

Many factors shape clients' and prospective clients' perceptions of the technical quality of the NGO services. The proximity of "bigger", more sophisticated services, the persistent association of the NGOs with family planning, confusion about the specific service niche of the NGOs, and even (appropriately) parsimonious drug dispensing practices may all contribute to 
underutilization of the NGO services. The NGOs can address some of these issues simply through better information. For example, respondents had somewhat mixed feelings about the referral systems of the NGO clinics and varying interpretations of what it implied about the technical competence of the staff. Some people clearly felt positive about it and seemed to understand that the clinic was intended to facilitate access to other services and that referrals to higher levels of care were an integral part of the services they provided. Others took it as an indication of the NGO's limited qualifications.

- It is common for rural people to use intermediaries such as family planning workers and village doctors to get access to services and a presumed higher standard of care from health facilities. This common practice could be highlighted in trying to spread the idea that the NGO clinics are meant to address a limited range of basic health needs for which the staff are well trained, and that they are also well trained in recognizing when referrals are needed and in making appropriate referrals - in other words, that they are dependable, and that they can help clients to save time and money by directing them to appropriate sources of care.

\begin{abstract}
Ability and willingness to pay
Need-based subsidization for the poor, however, is also an important aspect of quality from the client perspective, one that the NGOs are still struggling with. Even people can afford to pay sometimes question the legitimacy of the charges, often because they confuse NGO with government service providers.
\end{abstract}

- The NGOs need to clearly distinguish themselves from the government and clarify the role of service charges. This may be facilitated by passive changes (such as discontinuation of the "Green Umbrella" logo which perpetuates the association of the NGOs with government) and by proactively explaining to clients and community members why fees are collected and how this income is used.

The findings suggest that most clients think the current charges are reasonable, even though some have problems paying, but there is the danger that potential clients are not seeking out the services based on a perception that the cost is prohibitive. The failure to advertise the fact that subsidies are available may be discouraging clients from seeking services in the clinics. The NGOs are clearly aware of and concerned about this possibility and the staff is trying to identify individuals or groups who may be most in need yet not accessing services adequately.

- One important component of their efforts, supported by our findings, could be a transparent and clearly structured system of need-based subsidies.

- Credit systems could also be strengthened and extended to ensure that women who can and are willing to pay but who do not always have access to cash are able to avail of the services they need.

- Staff incentives to provide subsidies and credit should be designed to ensure they are consistent with the goal of maximizing access among the most needy in the communities. 
Unless and until they are able to access subsidized services from the NGOs, the safety net of government facilities will continue to be important for the poorest.

- The NGOs should engage in dialogue with government health facilities in the local areas where they work to ensure that women who travel far to get free services (and obviously need them) are not turned away.

\section{Changing a service delivery culture}

The findings also demonstrate that program staff and clients are indeed able to adapt to the new ways of thinking mandated by the new service delivery model. This is supported, for example, by the very positive finding that rich and poor are treated alike, and with respect, in the clinics. This was indicated by our observations of services and individuals' accounts of their own experiences, as well as by the perceptions of community members of various socioeconomic strata. Other evidence, however, suggests the persistence of norms and expectations from the past. For example, the still widespread perception that family planning services are offered as part of a national fertility reduction agenda presents a challenge to the NGOs as they try to implement a sustainable, client-centered essential services model. This perception can influence clients' attitudes regarding the legitimacy of charges for family planning methods and services, and also fosters mistrust between clients and providers.

- Ongoing emphasis on method-specific promotion by providers is therefore not only unnecessary, but also possibly counterproductive.

In conclusion, our findings from the rural sites strongly support the policy changes reflected in the government's integrated clinic-focused approach and the USAID NGO program. In implementing the transition to the new service delivery model, challenges related to access and quality have improved dramatically over time. Many of the issues the NGOs continue to struggle with as they introduce new services and program strategies will also likely resolve themselves as a function of time, particularly if the NGOs are able to sustain the level of service quality achieved so far. Several of the challenges the NGOs face, particularly related to costrecovery, are a function of expectations and norms from the past, and of incongruences between government and NGO policies and practices. As the NGOs, and the Bangladesh government, proceed with implementation of the integrated, essential health services model, additional strategies will be needed to erode the paternalistic service delivery culture that evolved in the context of a vertical family planning program. In pioneering the difficult task of transitioning from door-to-door family planning to clinic-based essential services, the NGOs have demonstrated both the potential of the new program strategies and the challenges inherent in such a major reorientation. As the government moves forward with its own transition, much can be learned from the NGOs' experiences in dealing with the complex challenges of pursuing simultaneously goals of access, quality, integrated service delivery, as well as cost-recovery. 


\section{Table of Contents}

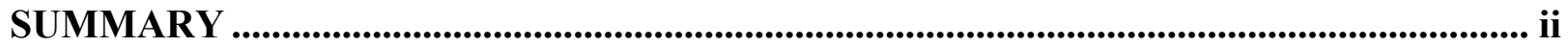

INTRODUCTION..............................................................................................................................

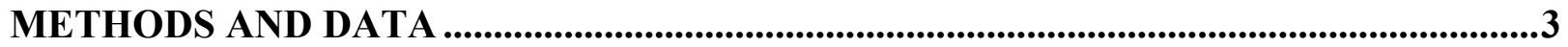

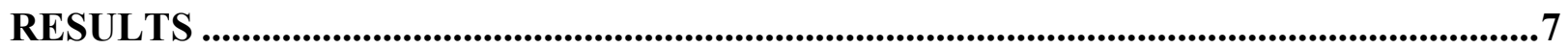

THE CBD PROGRAM PRE- AND POST-TRANSITION ……........................................

ACCESS TO FAMILY PLANNING SERVICES.............................................................. 10

Sustaining Contraceptive Use During the Program Transition ............................................10

Male Involvement in Contraceptive Supply ................................................................11

Access to Contraceptives Under the New Program.........................................................13

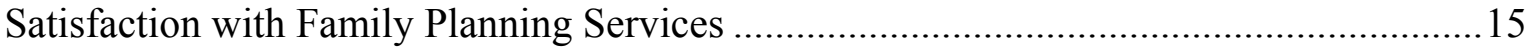

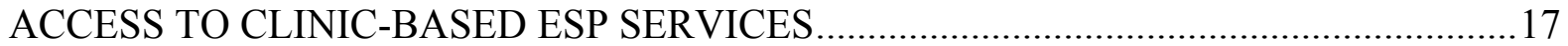

Knowledge of Services Under the New Program .........................................................

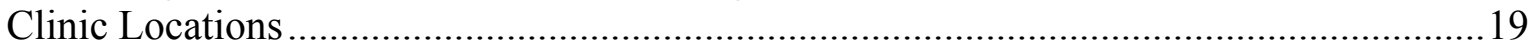

Men's Support for Women's Reproductive Health Care ...................................................19

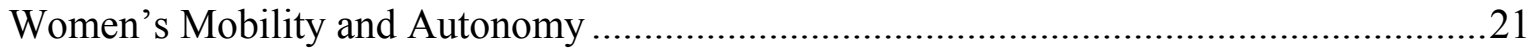

The Role of Depot Holders in Facilitating Access to Services.............................................2.

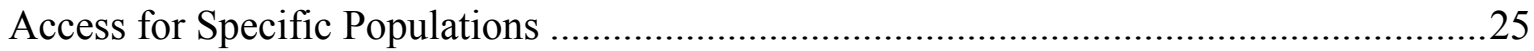

CLIENT SATISFACTION AND PERCEPTIONS OF QUALITY ………..........................27

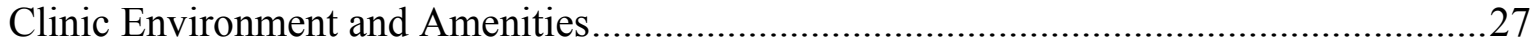

Convenience and Clinic Procedures .........................................................................28

Provider Behavior and Client-provider Interactions......................................................30

Range of Services and Technical Capability of Staff .........................................................32

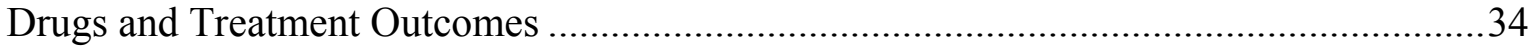

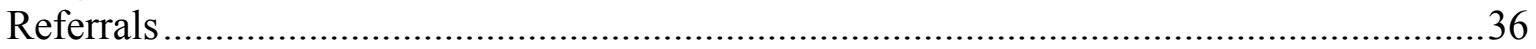

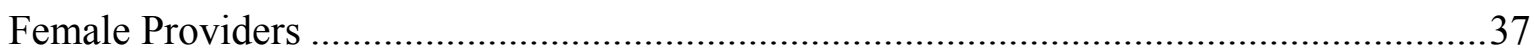

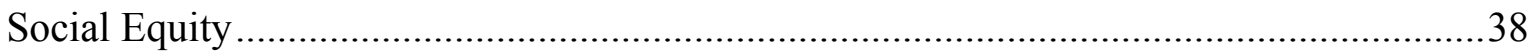

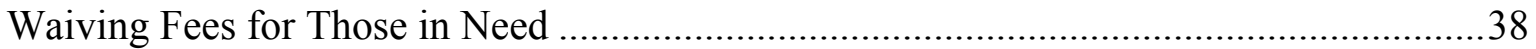

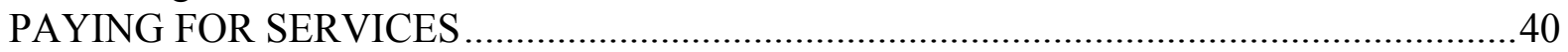

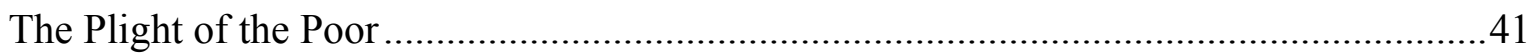

Expectations of Government and Confusion about the Status of NGOs ..............................41

Expecting Free Treatment for Side Effects....................................................................43

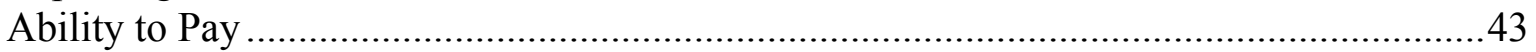

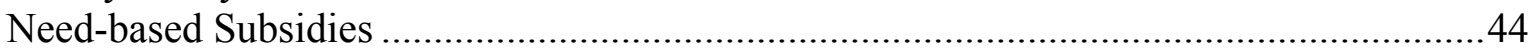

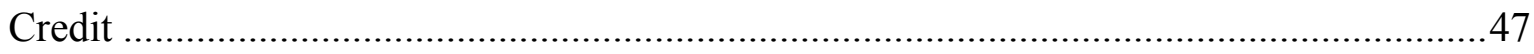

CONTINUITY AND CHANGE - LEGACIES OF AND DEPARTURES FROM THE

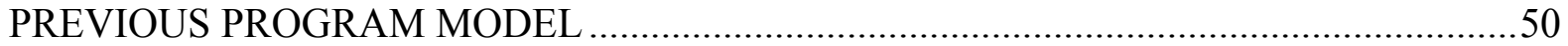

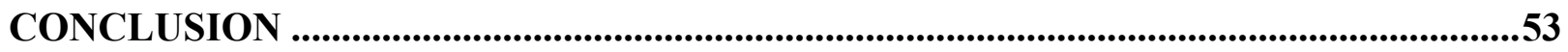

REFERENCES............................................................................................................................56 


\section{INTRODUCTION}

The Bangladesh Government's 1997 Health and Population Sector Strategy reflects many of the policies outlined in the ICPD Programme of Action. The Strategy calls for greater integration of family planning with health, ongoing stakeholder involvement in design and monitoring, a focus on users of services rather than demographic targets, improved quality of care, and a wider range of reproductive health services, with increased attention to maternal and adolescent health care, provided as part of an "essential services package" (ESP) (Government of Bangladesh Ministry of Health and Family Welfare, 1997). The current thinking within the government is that women should come out of their homes to receive reproductive health services. Plans are being developed to create "community clinics" where contraceptive services and information will be available along with other selected primary health care services that have been included in the ESP. The community family planning workers who now go door-to-door will receive additional training and will be based in the community clinics.

The United States Agency for International Development (USAID) directs a large share of its assistance in the health and population sector to NGOs in Bangladesh. Following a series of evaluations, assessments, and consultations with the Bangladesh government, USAID launched a new 7 year bilateral assistance program in health and family planning in mid-1997 which attempts to operationalize some of the fundamental elements of the Sector Strategy. Technical support is being provided by a group of national and international agencies led by Pathfinder International and the JSI Research and Training Institute. Many of the NGOs, in line with government and donor priorities of the past, had programs focusing on door-to-door family planning. Now that they have adopted the government's ESP approach, the NGOs have discontinued door-to-door contraceptive distribution. Services are being offered through clinics and satellite clinics (SC), with village depots for re-supplying contraceptives in rural areas. The NGOs are employing a variety of measures to improve the quality of services, to make the services more responsive to clients, and to increase their sustainability: the satellite clinic system has been expanded; standards for maternal and child health services, and training programs to support an expanded service package are being developed and implemented; clinic-based pharmacies and revolving drug funds are being established; the number of NGOs has been consolidated and management reforms have been instituted. The higher quality and greater range of services available in static and satellite clinics (with the opportunity for "one-stop shopping") is intended to attract clients as well as increase the impact of the services on health (Alauddin, 1999; Government of Bangladesh, 1996a, 1996b; Jamil et al., 1996; JSI Research and Training Institute. 1997; JSI Urban Family Health Partnership, 1998, 1999; Pinkham et al., 1995; USAID, 1996a, 1996b, 1996c).

The validity of several assumptions underlying these program changes has yet to be systematically demonstrated - for example, (1) that demand for family planning is not "fragile," (2) that constraints related to gender inequality will not prevent women from using the reconfigured services (and that the program changes will, in turn, not have negative social consequences for women); (3) that client priorities, and criteria for assessing quality in health care are well understood (and that they prefer "one-stop shopping"); (4) that clients and families are willing and able to pay for services; and (5) that longstanding programs and their clients are 
able to adapt to new models and ways of thinking. Earlier strategies sought to minimize the direct and indirect costs of family planning. By bringing contraceptive information and methods directly to women in their homes, the previous door-to-door system reduced both the time and money costs of contraceptive use for users to almost nothing - as long as there were no side effects or other problems. Even if they did not have cash at their disposal, women were able to adopt contraception with minimal involvement of men (Simmons et al., 1988; Schuler et al., 1995, 1996). The withdrawal of home-based services, provision of family planning in the context of other reproductive and family health services, and the introduction of cost-recovery measures such as higher service charges, have provoked concerns in various policy circles about possible detrimental effects on contraceptive prevalence and fertility rates, and on quality of care (cf. Hossain et al., 1995; Hossain and Phillips, 1996; Phillips et al., 1996).

The changes raise questions about the strength and nature of demand for family planning and other health services, and about balancing the goals of cost recovery with the needs of the poorest, most vulnerable groups. If the revised service delivery approaches are to result in more cost effective services and better reproductive health, substantial behavioral changes will be required on the part of clients, families and communities, as well as service providers. It is not yet clear if, and under what circumstances, clients will avail themselves of the various services that the redesigned program offers. Decision-making about the use of family planning and other health measures becomes more complex when women must go out of their homes for services, and must incur added social, logistic, and direct costs. These various costs bring up issues regarding how much a particular service is valued by the intended clients and their families, and how much importance women's needs should be given. The changes may create barriers for women who need reproductive health services. Or, alternatively, they may promote women's strategic interests by drawing them to clinics, and into the public sphere, where a variety of services and opportunities exists. By making it necessary for clients to take initiative and exercise their own judgment about what services to seek out, and to pay for, the new requirements may also produce a better informed, more discriminating clientele.

We have undertaken a multi-method, qualitative study looking at the effects of these policy changes on household-level decision-making regarding the use of family planning and other reproductive health services, on patterns of utilization of the services, and on client-provider relations and client satisfaction. This report presents findings from rural sites where the transition from home to clinic-based services has been underway. It documents how communities and programs are responding to the policy changes in a dynamic service environment and social context: how women who previously relied on home delivery now obtain contraceptives; how clients and families are responding to NGOs' efforts to improve quality and cost-recovery; and how clients and staff are adapting to the new program norms. The report shows how responses to the policy changes are shaped to a large extent by the experiences and norms of the previous family planning program. 


\section{METHODS AND DATA}

We have been working in two urban sites, and three rural sites. This report presents findings from the two rural sites, located in Chandpur and Kishoreganj Districts. The sites were selected in collaboration with USAID and Pathfinder International. It was decided that the sites should be in areas where implementation of the new program had taken place more or less on schedule, and where there were no special problems. In selecting the sites we only considered areas where door-to-door services had been in place and were discontinued under the new program. Each of the sites is served by a different USAID-supported NGO. To reflect the diversity of program experiences we chose one site in which an NGO previously working in the area continued under the new program, and another site in which a new NGO had begun working. Within each site the in-depth research is focused in 2-3 sub-areas, one area closer to the NGO clinic (within a onemile radius), and 1-2 areas farther from it (2-4 miles away), where satellite clinics are held. (For descriptions of the sites see attachment). To preserve the anonymity of the respondents, the names of the NGOs (and individuals interviewed) have been withheld from this report. The data are qualitative, consisting primarily of in-depth, semi-structured interviews with individuals, and supplemented with group interviews and observations in clinics and satellite clinics in each site. As far as possible, the group interviews were done with "natural" groups rather than groups formally organized by us.

Semi-structured data collection guides were developed for each type of data collected. Notwithstanding the use of guides, the interview technique was ethnographic in that the interviewers' objective is to understand the respondent's experience from her or his own point of view. Although the interviewer attempts to cover all of the topics in the guide, the discussion with the respondent is typically free-flowing, with the interviewer improvising questions to probe, check, and further contextualize what he or she is hearing. The interviewers were also asked to record any observations about the individuals being interviewed, and the circumstances of the interview, that may shed light on what is being said. Tape recorders were used in approximately $25 \%$ of the interviews. In most cases the recorded interviews were transcribed by the researcher who conducted the interview to ensure accuracy and the incorporation of nonverbal observations.

The data were collected by two teams of three to four interviewers each- one man and two to three women in each site. All of the interviewers have several years of previous experience in qualitative research; and several have MA degrees in the social sciences. The principal investigators provided additional specific training for this research project when it started, in terms of both subject matter and research methodologies, and this training was reinforced through ongoing feedback and periodic formal reviews. The training ensured that the researchers had a solid understanding of the broad research goals, specific questions being pursued, and appropriate ethnographic approaches, thereby allowing them to spontaneously develop questions to probe topics that arose in the course of the interviews. Based on their experiences in the field, the research team also contributed to the development of many of the guidelines and protocols that were used. As part of an iterative process, ongoing review sessions facilitated exchanges of information and ideas among the field researchers and investigators regarding both emerging findings and methodological issues, and necessary adjustments in the research focus and methods were made accordingly. Ongoing training also ensured researchers 
were familiar with informed consent procedures. Informed consent was obtained verbally from all respondents before formal interviews were conducted.

Data were collected between November 1999 and June 2000, but the period of reference spans several years, as respondents were asked retrospective questions about the door-to-door family planning period and the transition, which began in 1997. Rounds of data collection were spaced out over the data collection period in order to capture temporal changes in both program implementation and community responses. Changes over time were also captured through follow-up interviews with individual respondents. The interviews and observations were focused on the following topics:

- Sources of health and family planning services, and sources of contraceptives accessible to each village; knowledge and opinions about these various sources, patterns of utilization, utilization decision-making, and costs of services

- (Among women recently and currently using oral contraceptives) past and current sources of supply; initial understanding of, and reactions to, the transition; sources of information, knowledge of, and strategies for accessing alternative supply sources

- Men's knowledge and opinions about the program transition, and roles in obtaining oral contraceptives

- Service delivery and client provider interactions in NGO static and satellite clinics, as well as other facilities near the study sites

- Attitudes of NGO clinic staff regarding the services offered, their relations with clients, and problems they face in implementing the new service delivery policies

- Experiences of recent clients, including decision-making in the home prior to the clinic visit, and assessments of the services they received

- Men's attitudes regarding women's use of clinics and satellite clinics

- Situations and perceptions of women who have not visited the NGO clinics and/or other clinical services

Three rounds of data collection yielded 321 interviews with 249 women, 72 men, and 10 group interviews (one with men, nine with women). In addition, researchers' unstructured ethnographic fieldnotes were collected and analyzed. Respondents were identified using a combination of convenience and purposive sampling, the "snowball" method, key informants, and service records. Although random procedures were not used, efforts were made to ensure representation of key population subgroups per the research interests or site composition. For example, newly-married and destitute women and clandestine family planning users were sought out in light of concerns about their access to the new program relative to other groups. Similarly, when it was learned that there were women working out of the home in a site, these women were purposively interviewed to understand what unique issues they face in using the new services. 
Table 1. Interview Types and Numbers Conducted in Rural Sites

\begin{tabular}{|l|r|r|}
\hline Interview and Respondent Types & Kishoreganj & Chandpur \\
\hline Total Number of Individual Interviews & 168 & 153 \\
\hline Women & 136 & 113 \\
\hline Men & 32 & 40 \\
\hline Types of Individual Interviews & & \\
\hline Former CBD Workers & 2 & 2 \\
\hline Clinic Observations & 6 & 4 \\
\hline Client Interviews and Observations in clinics & 16 & 17 \\
\hline NGO Program Staff (Depot Holders, clinic providers, & 14 & 9 \\
\hline Community Mobilizers, Managers) & & \\
\hline Other Providers (GOB, other NGOs) & 3 & \\
\hline Observations of NGO Outreach Activities & 4 & 2 \\
\hline NGO Outreach Participant Interviews & 3 & 7 \\
\hline Former Door to Door Clients/FP Users & 34 & 34 \\
\hline Husbands of former Door to Door Clients/FP Users & 8 & 8 \\
\hline Depot Holder Clients & 7 & 7 \\
\hline Recent Clinic Clients & 31 & 30 \\
\hline Husbands of Recent Clinic Clients & 9 & 8 \\
\hline Community Perceptions and Experiences of Health Services & 15 & 12 \\
\hline Special Groups (destitute women, newlyweds, non-FP users, & 13 & 5 \\
\hline working women) & & 4 \\
\hline Other Husbands of Women Interviewed & & \\
\hline Other Key Informants & 3 & \\
\hline Group Interviews & 7 & \\
\hline
\end{tabular}

The use of multiple methods of data collection and respondent types allowed for triangulation of the data in the analysis at both "global" and micro levels. For example, researchers' observations of the various clinics and interviews with staff provided an overall context for understanding the experiences and perceptions of clients and community members solicited in interviews. In addition, observations of individual client visits provided material that could be used in immediate follow-up interviews with those particular clients to ask specifically about their experiences and perceptions based on what was observed. Similarly, by interviewing different types of family members (husbands and wives, "seniors" and "juniors") we gained a richer understanding of different perspectives on decisionmaking around reproductive health services; interviews with different members of the same family facilitated in-depth information about specific familial dynamics around these issues.

Preliminary data analysis began concurrently with the data collection, so that insights gained were further explored in the field. Furthermore, periodic consultation with Pathfinder International allowed the investigators to contextualize the findings and to identify further areas of inquiry that could be used to inform the process of program implementation in the near-term. Field researchers were also involved in preliminary analysis. The principal investigators conducted content analyses of the interview/observation transcripts to identify statements and reported behaviors involving family planning and reproductive health decision-making, gender 
dynamics, and service experiences. They organized the material thematically, juxtaposing data from the various types of interviews/ observations, and exploring apparent contradictions. After reading the transcripts several times to search for supporting material and counter-evidence, the principal investigators presented the themes identified to the field researchers, who were encouraged to challenge the interpretations and to offer counter-explanations and evidence; or, if they agreed with the interpretations, to provide additional supporting evidence. Also with the involvement of the field researchers, we created systematic tabulations of material from sets of similar interviews. For example, we reviewed all transcripts from interviews with recent clients to determine what proportion needed credit and subsidies.

Final data analysis was performed using the ethnographic software package SPData. A coding scheme was developed on the basis of the preliminary reviews of the transcripts, and data were coded both categorically (for quantitative analyses) and qualitatively using passages of text from the interviews and observations. Periodic comparisons of coding by different investigators were made to ascertain reliability. If coding discrepancies were found the investigators discussed individual cases until consensus was reached. 


\section{RESULTS}

\section{THE CBD PROGRAM PRE-AND POST-TRANSITION}

Under the new program, former clients of the home delivery system are expected to obtain contraceptives from pharmacies, or from clinics or satellite clinics where they can also access broader reproductive health services. Community mobilizers use a variety of strategies to inform people about the clinics and to encourage them to avail themselves of the services. In addition to satellite and static clinics, village-level depot holders (DH) have been established to sell pills, condoms, and basic medicines and to help organize satellite clinics in designated areas of approximately 120-150 households. Some door-to-door workers have become depot holders, and a few have been recruited by the clinics. The depot holders do "selective home visitation" to make services accessible for women with special needs or constraints. Although door-to-door family planning had been officially discontinued in all sites in the late summer of 1997 (and replaced by selective visitation in rural sites), during the research period the sites varied in the extent to which innovations in the clinic-based services were in place.

The findings show variation in clients' and communities experiences of the service delivery transition, despite the small number of sites included in the study. This is partly because service delivery models in the study sites and subsites varied even prior to the transition. Under the old program there were differences among sites and subsites in the implementation of the door-todoor system, particularly in the frequency and location of visits by family planning workers, and the range of services and information provided. For example, in many cases workers did not visit every home; especially when the workers resided in the community where they worked, women often went to their homes to pick up supplies of oral contraceptives. Some workers were more regular than others in their visits. There were also differences among the study sites in pricing policies and the degree of flexibility in their implementation.

Since the program change, sites and subsites have also varied in the extent to which door-to-door services have been discontinued, and in the extent to which clients were aware that the program was changing. There was no formal notification of the program change in these sites. A few of the former fieldworkers did unofficially alert their clients, particularly if they were asked by women who had noticed the fieldworker's absence. But most avoided informing the communities of their termination (and therefore the program change), offering excuses such as illness to explain their absence to clients. During the interim period before the new program was established, some family planning workers continued informally supplying women with contraceptives out of a sense of responsibility or loyalty, hope of being rehired under the new program, or to avoid the shame or loss of status associated with losing their jobs. Unemployed workers either distributed existing stocks of oral contraceptives, or obtained them from government outreach workers or purchased them in the market in order to continue to supply them to their clients. Some tried to maintain supplies for all their former clients and others did so selectively. For example, some of former fieldworkers eliminated clients who had previously taken contraceptives on credit and could or would not pay what they owed.

Somewhat perversely, the dedication and loyalty of the former door-to-door workers to their clients, and their refusal to believe that the work they were so committed to could really end, 
may have contributed to confusion and misunderstanding about the NGOs' new policies in the communities they served. One depot holder who had not informed her clients of the official program change said, "....the villagers told me that they were in deep trouble as I was no longer going to their houses." She purchased pills from the market and re-sold them to her clients at no profit. When asked by the researcher why she bothered to do this she replied, "I had developed sympathy for them by doing this job for many days. That is why I could not stop myself in their time of misery." She felt that her clients were dependent on her, "All of [these women] are my clients. They would immediately conceive if I did not give them pills. They all had become dependent on me and there were many who were not in a financial position to buy the pill from anywhere else. That is why it turned out to be a duty of mine and I performed my duty from my heart." She also maintained home-delivery in hopes of getting her job back: "In the meantime I heard from the office that the management would keep the persons who worked sincerely. I did the work (door-to-door supply) with that hope also." Another did not continue supplying on her own and felt bitter about the circumstances surrounding her termination,

"Many people think that I was terminated from the job for taking money for pills, injections, and condoms. Many women criticize me, which is very sad for me. I had a lot of unexpected work because I had to take taka from women, but in spite of this I was terminated"

In both rural sites former family planning workers were re-employed as depot holders a few months after their contracts ended, at about half their former salaries, and one or more former depot holders were also re-employed. (This contrasts with the urban NGO programs where there were fewer employment opportunities for the former door-to-door workers because of the educational requirement set for the "service promoters" who are responsible for community outreach.)

The new official policy called for targeted visits only to specific types of women but, again, the extent to which the new (or re-deployed) depot holders followed this policy varied considerably. One such worker, during the interim period before the new program started, purchased two brands of oral contraceptive from the market and resold them at a slight mark-up to many of her former clients ( to "those who behaved nicely....nice behavior means they always gave me the money on time, or would pay me back when I gave them the pills on credit"). She supplied a few other clients with free oral contraceptives that she got from a government worker. When she was re-employed at a lower salary level as a depot holder, she decided that it was no longer worth the trouble to go door to door. Thus many women in her assigned area only learned about the change in the program when she told them they would have to pick up their supplies at her home; now some of them come to her home and pay the nominal charges, others now get free oral contraceptives from a government worker who brings supplies to a relative living in the area, others get the pills through their husbands, from commercial outlets, and still others have switched to injectable contraceptives which they get from the NGO clinic (relocated, and now more accessible than it was in the past).

In a nearby subsite, the former door-to-door worker similarly continued to supply her clients during the interim period before she was re-employed as a depot holder, and she continues to deliver pills door-to-door even now, for less pay (except that she dropped some clients who 
refused to pay their debts). She feels strongly that her clients are dependent on her and would not be able to obtain contraceptives on their own. Another former door-to-door worker who became a depot holder did limit her home visitation under the new program and was initially accused by women in the community of neglecting her job until a community mobilizer explained the new system to them.

Some of the depot holders seemed content to not have to do extensive home visitation, but others felt that even selective visits to those with a special status (e.g., newlyweds or pregnant women) or who are socially constrained (e.g., clandestine users or women with low mobility) was not sufficient. One depot holder who mistook our researcher for an official of the NGO explained to her, "Apa, you make rules that I should not be visiting houses but it is good to make visits and be in touch with the clients. Otherwise I cannot keep track of the clients. If I go to their houses sometime then I could talk to them and I can get to know about the methods that they are taking." A depot holder in another subsite continued as best she could to visit all clients, even those who lived nearby and were clearly mobile. There, we interviewed a substantial number of clients who seemed completely unaware that there had been a change in the door-to-door policy. 


\section{ACCESS TO FAMILY PLANNING SERVICES}

The continuation in varying degrees of door-to-door services following the official program change did mitigate the effects of transition on access to family planning for many couples. However, not all women benefited from the unofficial continuation of home-delivery, and the sustained use of family planning we observed in these sites throughout the program change reflects a combination of strong demand for family planning, changing social norms, and increasing use of alternative sources of healthcare.

Consistent with our findings from previous research (Schuler et al, 1996, 1997) as well as the findings from research on the program change in urban areas, men and women are strongly committed to fertility control. Although the program change in the rural sites did impose both inconvenience and real hardship for some women, discontinuing contraceptive use was not considered an option and only occurred (for short intervals) after women had exhausted all perceived sources of supply. Family planning is now widely regarded as a basic necessity of life. One woman explained why nobody stopped taking their pills after the "Apas" stopped coming in such terms: "The way in which people manage their rice and fish - they manage to get pills in the same way." Another man acknowledged that men do not really like their wives to go out to obtain pills and condoms as is now required, but similarly described it as a necessary requirement of life today (and something the government wants). In fact, the extent to which fertility control has become such a widespread norm (and the government's propaganda around family planning has been internalized) was illustrated (somewhat perversely) by a woman's explanation for why she did not go to a clinic to receive a TT injection during her pregnancy: "I did not take any vaccine during my pregnancy because I felt shy. When I go to the doctors then they will ask how many children I have (6) and I feel shy. There are ten people in the place where the injections are given and they would also know (hear) how many children I have."

\section{Sustaining Contraceptive Use During the Program Transition}

The majority of women who did not continue to receive home supply under the new program were able to adapt to alternative sources of family planning fairly easily and quickly, after an initial adjustment period, if not right away. Problems women had adjusting initially were usually a function of inadequate information about the program change. Of 43 women we interviewed who had regularly received services in the home during the doorstep program, only 12 reported having learned (by various means) of the termination of home supply in advance. ${ }^{1}$ Lacking information, some women waited needlessly for the family planning worker to arrive, and/or did not know or were confused about where to go instead. Despite the lack of notification and information, however, only 9 of these women had a problem sustaining contraceptive use during the transition for reasons that were ostensibly supply-related.

\footnotetext{
${ }^{1}$ A few of the women who had not been informed did not actually experience a transition as door-to-door services continued in their area uninterrupted
} 
The ability for most women to continue using family planning uninterrupted is partly a reflection of prior experience with alternative sources during the doorstep program. The majority of women in these sites reported that the door-to-door system had been for them reliable and convenient. Most women experienced very infrequent delays in the family planning worker's visits and rarely any that resulted in gaps in supply. Many of the workers would warn women if they were not coming on time the following month and advise them to take additional supplies. They also generally advised women to borrow pills from neighbors if ever they were delayed in coming. However, as in our other research sites, even relatively high reliability of the door-todoor services did not necessarily translate into dependence on the system and women did have experiences with other sources of family planning prior to the program change.

Those who occasionally experienced gaps in supply developed alternative strategies such as borrowing from neighbors or obtaining pills from the market through their husbands. A number of women also chose to purchase more expensive brands of oral contraceptives from the market, believing them to be of higher quality. Some women also reported that they sent their husbands to buy pills rather than getting them from the family planning worker so that they would not have to cover the expense out of their own money. In this way the program change inadvertently worked to their advantage with regard to paying for contraception. For example, one rural woman who had been offered pills by the newly established depot holder in her village elected to have her husband continue to obtain pills from the market after the program change since he would then automatically spend his own money and she would not have to bother to arrange the money herself - either by asking her husband or using the money she already had set aside for family expenditures. Another woman who chose to continue getting pills through her husband from the market commented that, "men have taka but we do not have taka. The apas (door-todoor workers/depot holders) provide pills to women but women cannot get taka from men. So if my husband gets pills then I do not have to pay." Even though she has to remind him and sometimes he is late, she prefers this system: "It is advantageous for me as my taka remains intact. To manage taka I have to sell an egg or other things. [If my husband brings the pills] it is not my headache, rather this is his headache."

\section{Male Involvement in Contraceptive Supply}

As in our other sites, men were instrumental, in varying degrees, in sustaining contraceptive use not only during or after the program change, but also under the doorstep program. When couples wanted to use methods from the market, or were forced to deal with occasional gaps in supply from the family planning worker (unusually rare in these sites), men would often have the responsibility of obtaining pills from local shops. But in some situations - i.e., where the program transition was particularly abrupt, or where women had more restricted mobility men's participation in family planning procurement increased and was crucial for sustaining family planning use after the termination of home-supply. As one respondent described in a subsite where the transition was rather abrupt, "everyone was in trouble after the Apa stopped coming, but the capability to get rid of that trouble was not the same for all" - and depended on husbands' willingness to help.

The main barrier to increased direct participation of men in family planning in the sites was "shyness", and not indifference to fertility control. There were a few examples in the study sites 
of men refusing to help get family planning because it was not their "duty" or it is a "woman's affair," or of women excusing men's lack of involvement as a function of their inherent inability to perform such roles. But for the most part men's lack of or inadequate involvement in family planning was rarely due to absolute or explicit resistance or abdication of responsibility, and almost never due to weak demand for family planning. Men seem to have fully embraced the small family norm, for both economic and social reasons and, and their demand for family planning is sufficient in most cases to make men overcome their reluctance and procure methods, particularly when there appears to be no alternative.

"Men are also interested in keeping the family small. That is why even though they were annoyed (when doorstep services stopped) they did not deny in helping their wives acquire methods."

Respondents often attributed this commitment to fertility control and family planning among men to the influences of mass media campaigns on television and radio. For some men, desire for family planning clearly reflects a response to perceived new social norms prescribing fewer children "maintained" well, rather than large families, as what is respectable and part of being a "proper" man.

Men's hesitation and "shyness" seems to instead reflect primarily their long-standing marginalization from the family planning program, one of the legacies of which is the ongoing belief that family planning is predominantly for women - their unique right and responsibility. One man we interviewed was more willing to have his wife purchase pills from the market, and confront possible social sanctions for violating purdah and moving in a very public place, than to get them himself because he feared and felt embarrassed by "people's comments." He thought that in contrast it was alright for women to buy pills from the market because they do so for their own "necessity."

There were several other examples of women transgressing social norms more than men in order to sustain family planning use, even though the problem was clearly men's personal inhibitions around family planning, not their opposition to fertility control. For example, one couple we encountered very much wanted to practice family planning and during the doorstep program they colluded to use condoms secretly without the husband's mother's knowledge since she objected to their use of contraception. After the program change they had a hard time sustaining use. The woman's mobility was also restricted by her mother-in-law so she could not easily go out of the home to access supplies under the new program. She and her husband knew they could get condoms at the pharmacy but he felt too shy to do so and as a result she had to repeatedly defy her mother-in-law and leave the home to collect them herself.

Another woman commented that, "The men do not want to bring family planning from the hospital because they feel shy. For this reason now the women themselves go to the hospital on their own accord." This observation and the examples noted suggest that evolutions in social norms around family planning for men have lagged considerably behind those for women in important ways and that more could be done to foster social acceptability of men's direct participation in family planning. What is promising is that men do seem able to adapt to this role over time and, presumably, with positive reinforcement. Much of men's “shyness" related to 
family planning procurement seemed to decrease the longer they were forced or chose to be involved.

Interestingly, a number of women did not share the view that family planning was their unique concern and either viewed positively their husband's [increased] participation or, conversely, resented his inability or unwillingness to do "anything other than earn money." As one women who felt her husband was appropriately "conscious" about family planning noted,

"This matter of family planning involves both the wives and the husbands. It is not the exclusive matter of the husband or the wife. I got the pills sitting in my house earlier, but now my husband brings pills for me. There is nothing bad in it."

Some women even take pride in their husband's involvement. For example, one woman described how the fact that her husband never forgets to bring pills shows that he "gives importance" to her affairs (notice, however, that she still considers family planning to be her affair), as does the fact that he is willing to pay for the more expensive brands of pills from the market. Other women also appreciate aspects of male involvement in family planning such as showing concern about side effects and reminding their wives to take their pills.

Some respondents perceived that the program change had in the aggregate a positive effect on men's level of involvement in family planning (and that this was a positive outcome),

"Now many men bring methods for their wives. Before women did not have to talk about these matters with men as much. Now men also appreciate the need to have fewer children."

However, others lamented that this increased involvement was rather short-lived and superficial. For example, one depot holder noted that men did become more involved when doorstep services ended but "again left the scene as soon as the new program came" and women could access methods from the satellite clinic or depot holders. Another depot holder who was a former family planning worker also reported that though men were forced to become more involved in procuring pills for their wives as a result of the end of doorstep services, there was no "big change" in the men. When asked to explain, she said "big change" would mean that they keep information about family planning, or share the responsibilities with their wives, but this sort of "big change" did not happen.

\section{Access to Contraceptives Under the New Program}

Where the new system created problems for some they usually had to do with distance and/or cost. The efforts of these women to sustain contraceptive supply under the new program further demonstrated the strength of demand for family planning and determination to continue using even when obtaining methods is experienced as difficult.

In one site, several women who did not know about the NGO, or thought they could not afford to purchase methods from there or from the market switched to nearby government services for contraceptive supplies after the program change. However, after a while the government 
providers were trying to maintain the demarcated $\mathrm{NGO} / \mathrm{GOB}$ areas and began turning away family planning clients and telling them to obtain methods from the NGO. For several women this was an inconvenience (to travel far unnecessarily, and to then have to find an alternative source), but for other women it created real problems. A woman who had inconsistent access to cash was going occasionally to the government facility to get supplies instead of to the depot holder (DH) in her village. Eventually they turned her down and rudely told her, "There are women in your area from whom you can acquire your methods. Why did you come here instead of taking your methods from them?" She explained to the government workers, "I would not have gone through so much hassle of coming here if I had money on me. I only came here because I do not have money, so that I can get pills free of cost." The government providers were very reluctant, and only gave her pills after she insisted. This is not a case where the woman simply did not know about the NGO providers, or where she was objecting to the cost but could afford to pay - she said explicitly that the price of the depot holder was reasonable, but just that it is sometimes a problem for poor people, like herself, to acquire that amount. Another very needy woman with 6 children was turned away by the GOB providers and ended up discontinuing method use while she tried to figure out how she could get the DH to advocate on her behalf to the NGO clinic to give her a discount, something she perceived she could not ask for herself.

Similarly, a very poor woman made several attempts to get methods from the government provider even after she was turned down: "I tried many times to get birth control pills of injections from [the government] hospital but they did not give me any. Every time they told me to get my methods from the voluntary clinic but since my family is very poor it is not always possible for me to get methods every time." Trying to maintain demarcated areas is a good strategy in principle, but the poor suffer if they are denied access or treated badly. Women who travel far to get free services obviously need them and should not be turned away.

Another woman in this situation could have been helped simply with better information. She was using multiple strategies to sustain her supply and at the time we interviewed her was very concerned about her ability to continue to do so. For two years after the program change she obtained pills from the government hospital. When they finally turned her down she received pills from a neighbor and thought when they finished she would purchase pills from the market, even though money is a problem. "I need to take pills even if it costs money. It is necessary for me. There is no income, what gain would there be by making the household larger?" Although she was poor, her problem seemed to be that she simply did not know enough about her options. She believed that the NGO clinic was farther away from her home than it really was and also was not sure whether pills were available there: "The voluntary clinic is very far from my house. I have never been there. I do not know whether oral contraceptive pills are available in that place. That is why I am wondering whether they would send me back as well if I go there."

Clearly the local level NGO staff are concerned about the possibility of losing family planning clients, and they have improvised strategies to prevent this from happening. At the satellite clinics, the staff compare the attendance list with village injectable users. If there are any people who failed to show up at the clinic, then the DH takes the paramedic to these women's homes to administer contraceptive injections. For some clients door-to-door services, or some type of assistance in getting access, may continue to be needed. In others it is clearly an unnecessary luxury. One client said she likes going to the satellite clinic (SC) for pills (it is near her house) 
but there is no need to go because the DH brings the pills to her home. In other cases husbands have stopped purchasing oral contraceptives in the market because the $\mathrm{DH}$ had offered to deliver them.

Local NGO staff are also aware of the need to contact individuals or couples who may not previously have had contact with the program, or with reproductive health services. For example, DHs keep track of marriages in their areas, visit the newly married women, talk to them about contraceptives, and help them in raising the subject with their husbands. The NGOs also hold meetings for newly married couples.

\section{Satisfaction with Family Planning Services}

Many appreciated the convenience and personal relationships they had with FP workers in the doorstep program:

"I got pills sitting at home and also got them for free. [The family planning worker] was like a sister to me. She came and chatted with me. We would sit together and have chewing leaves and after that she would leave."

However, many women acknowledged that in practice the doorstep services were less than the ideal and often created more hassles for them. As one woman commented after the program change about the irregularity of the home visits, "The government sent the Apa to help us people but she did not visit us properly. It was good when the pills were given at home because I did not need to go out of the house then, but how would it be good if she did not visit us properly?"

Many women's complaints about the door-to-door program related to the limited skills of the fieldworker and the narrow range of services and advice she provided. For example, one man was asked if he ever discussed his wife's severe headaches with the family planning worker and he said he did but that he never received any useful advice from her. He reported that she used to say the same thing all the time - "Maybe the pill was not taken at the right time" or "Maybe the pill was taken on an empty stomach." Another woman commented about the quality of help from the old fieldworker (now DH) regarding general health, "We would never tell her about all these things - we have a doctor near to our house, why should we tell her?" Another woman was concerned about bleeding she attributed to side effects from the pill and became very dissatisfied with the family planning worker:

"I told [the former FP worker] several times about my problem. But she could not show me any good treatment. She only told me to take the pill regularly and that the pill will be habituated in good time. I would have died if I had not gone to a doctor. In such a complication one could at least suggest doing something. If it were not possible, one should suggest going to a doctor. But she said nothing. I was very much angry at [the FP worker] for a long time."

Some felt that the fieldworker was simply too uneducated to be helpful, "We did not ask (the FW) anything and she did not say anything (advice/counseling). I know things a bit more than she does - why would I ask her?" Another woman reported that the FW would not give any 
services or advice regarding general health or reproductive health. According to her this was a reflection not only of the FW's limited skills, but also of the limited options available under the old program: "What advice can she give? We ourselves know that if we take pills then we should take better pills and then we will not feel dizzy. Now, there is no use of knowing it. Because we can not take those pills due to lack of money. In that case what else she can do?" Similarly, a male respondent noted that although the FW did her job very well in the beginning, later his wife was not happy with her family planning method and the FW could not suggest any other suitable method for his wife. He was also frustrated that she could not find any solutions for her other problems either.

Many women reported that the new system was convenient and more reliable (particularly those living near to one of the clinic sites). They felt that, while convenient, home supply was really not needed for them. One woman found it easy to get pills from the static clinic because it was located on her route to a school where she worked. Another woman speculated that the reason the former FW (now DH) no longer comes door to door is that she cannot sell her pills as easily now since women are choosing to get their own pills from the clinic (rather than seeing increased clinic use as a function of ending door-step services). Women also appreciate having access to more technically skilled providers and a broader range of service options, particularly for contraceptive side effects - things that are apparently becoming more available under the new program. One woman commented that she would definitely go to the NGO clinic regularly for family planning since she can talk to anyone about methods at any time. Similarly, another woman noted that the new program is preferable because the old family planning worker did not know anything and now she can go out and talk to the new "apas" and get better advice about side effects - something she said was not possible "sitting at home." 


\section{ACCESS TO CLINIC-BASED ESP SERVICES}

\section{Knowledge of Services Under the New Program}

Respondents reported learning of the NGO clinic-based services from a range of sources. These included depot holders, neighbors, Community Mobilizers, posters, signboards for the satellite clinic, and community-wide "miking." The depot holders were named by respondents as the most common source of primarily basic information about the clinics (e.g., their physical existence and location) and seemed to be perceived as a reliable source except in one subsite where a few respondents had heard about the clinic from the DH but did not think she was a credible source because she was "new."

Knowledge of the services in the various sites was uneven in terms of both content and coverage, but was clearly improving over time. Particularly in the earlier rounds of interviews we found that, for example, a number of people had not heard about the satellite clinic from the depot holder (despite extensive contact with her) and even people residing quite close to the site did not understand what was happening there. Similarly, several respondents who had had contact with the satellite clinic and/or the DH knew nothing of static clinic (though in some cases it is more appropriate to refer people to government facilities for higher levels of care because of distance, and we did interview one DH who was doing so for this reason).

Respondents' knowledge of the services available at the clinics was also uneven, but similarly improving over time. During the period of data collection for this study, the NGO clinics were still primarily associated with family planning, but many respondents did know of other services available there, and we found some evidence (again, uneven) of providers marketing the clinics for more than their family planning services in the context of a clinic visit. Numerous respondents spontaneously mentioned knowing that the clinic provides treatment for "all sorts of diseases" and several referred to specific services, particularly those "for the pregnant woman." There were particular subsites, however, where respondents had very low knowledge of the broader "ESP", and overwhelmingly associated the clinics (both satellite and static) with family planning. This seemed particularly true in areas farther out from the clinic sites, suggesting that the coverage of community outreach has been somewhat uneven. Outside of the clinic context, women reported learning about the various services available from the depot holders, Community Mobilizers, and also from other women who had used the clinics for these purposes. Community Mobilizers (CM) appear to be capable of disseminating more sophisticated messages about the NGO services (e.g., the full spectrum of services available) and health issues more broadly. However, our data suggest that their performance of these roles is again uneven. Our researchers found that in one site the $\mathrm{CM}$ appeared to be an effective communicator and was performing a unique role in accessing community members and informing them about the program. However, in the other site they felt that the $\mathrm{CM}$ resembled somewhat the role of the Family Planning Inspector (FPI) of the GOB program, often criticized as being redundant with other providers and performing (unnecessary or ineffective) supervisory functions.

Despite the lag in information and unevenness in community knowledge of the new services, we did find women who had obviously had minimal if any contact with the formal program - either 
outreach staff or the clinics themselves - but yet knew a surprising amount of detailed information about what services were available, clinic procedures, service charges, etc. (even if some of that information was incorrect). The familiarity of these women with the services, who were not using the clinics because they felt they could not afford the service charges, reflects both the demand for health and family planning services and the extent to which (in part as a function of that demand) people will share information (for better or worse) with others in the community about various services and their experiences with them. This diffusion of information is both an asset and liability for the NGOs as they seek to disseminate information about the services, but also struggle to convey unavoidably complicated messages about service procedures, such as payment and referral systems (see discussions below).

One gap in information that did create difficulties for some respondents concerned the timing of the satellite clinic visits (again, something likely to resolve itself over time provided the clinics are held fairly regularly and the mobilization around the clinics dates is maintained systematically). All the depot holders we interviewed mentioned notifying people of the satellite clinics as an important part of their jobs - they do so both in advance and the day of the clinic, and some reported advertising other services available in addition to family planning. Several of them also said they make special efforts to ensure women using injectables and pregnant women knew about the clinic. Respondents also said that they were notified of the satellite clinic by the Community Mobilizers and told what they should go there for. However, it is possible that it will be necessary to continue emphasizing this role, even after clinic attendance appears high. One depot holder reported that now she only really focuses on selective notification of the satellite clinic since she believes that everyone now knows about the clinic and what is available there. Our interviews with respondents in the area where she worked suggested otherwise, however. Another depot holder said that she did not make any special effort to alert pregnant women about satellite clinic days for their TT injections. Yet we found in this area examples of women unable to get their TT injections at the satellite clinic because the team had come and left without them knowing, so they went to THC instead.

Similarly, women in other sites also reported that at particular times they would have gone to the satellite clinic but did not find out in time, or they tried to go and found that the clinic was not being held. These women also managed to get care (either routine services like TT injections or curative care) elsewhere but were frustrated by the wasted effort and, for some, unnecessary hardship. Perceptions of unreliability (for whatever reason) may affect women's own willingness to try to use the services again in the future, as well as influence how they reflect on the services to others. One very poor pregnant woman said that when the satellite clinic team came to the site, they called her to take her tetanus TT injection. She said that when she went there later, the doctors told her that they ran out of TT injections and that there was nothing they could do. She did not go there anymore after that because, "I do not know whether they came again. They would have called if they were here."

The depot holders appear to be an important (or at least potentially important) source of information about the new NGO services in the community, and clearly have the closest ongoing relationships with clients and potential clients, and it is therefore tempting to focus on their performance as a way of dealing with ongoing gaps in knowledge of the services. Indeed, even as late as Novermber 1999, we interviewed depot holders who clearly did not know enough 
about the new program to market it well. While addressing the depot holders' limitations on their ability to perform existing responsibilities can only be helpful, it is probably important that they not be given additional responsibilities, and that more emphasis should be placed on the reinforcing or unique activities of the Community Mobilizer in disseminating information about the clinics and services available.

\section{Clinic Locations}

Distance to services is an important factor for many respondents in deciding where to go for healthcare and, according to some, in increasing service utilization overall. Several respondents thought that the more widespread availability of services (and therefore proximity to a greater number of people) was a key reason for what they perceived as an increase in women's use of health services (and clinical contraceptive methods) compared to the past. In some cases people are clearly willing to pay more to be able to access services (in a clinic or at the market) without having to travel far. One woman said explicitly that she thinks the service charges of the NGO are reasonable and a very worthwhile expenditure for being able to go nearby for services (rather than the government clinic farther away). But others will travel quite far (e.g., over an hour by foot) to government services in order to save money. Clinic proximity is also believed by some to be an important factor in their families' willingness to let them travel to use services. As one woman commented,

"Why would my husband object? The clinic is close to our house."

In one of the sites where the static clinic was situated very near the market, respondents had mixed views on the importance of its location. Some felt this was not a problem,

"What is wrong that it is in the market place? Do I go alone? Everybody goes there rightly. If everybody can go, why would I find it troublesome?"

or even advantageous as they could economize their travel by accomplishing other errands on the same trip. Others, including women who were able to travel alone and over some distance, felt like the location was a serious, if not insurmountable, disadvantage. One commented that she does not mind traveling to the clinic, but finds going through the market troublesome because she has to "pass through so many people." She prefers the old (door-to-door) system because, "not everyone's husband likes his wife to go outside, going through so many people inside the market." However, she did manage to go to the clinic regularly to get her method.

\section{Men's Support for Women's Reproductive Health Care}

Many women do believe that their husbands are supportive of them and want to "take care" when they suffer health problems. Men have long been played a role in facilitating women's access to healthcare by bringing medicines from the market and village doctors to the home when problems were perceived as serious. Although men's efforts on behalf of their wives' health are usually regarded as pragmatically motivated (so that she is able to perform her domestic responsibilities and "maintain the family"), some women say this is a sign of their 
husbands" "love" and "attraction" and most women who feel they receive it seem to take pride in their husbands' care and concern.

Men in general also seem to be supportive of women using clinics, but this support is often quite passive. In many cases men do little or nothing to actively facilitate women's access to clinics. For example, husbands rarely take their wives to clinics, except in cases of severe illness. Women usually explain that either it is not necessary, or that the husband is too busy with work to go, and do not seem to find this troublesome or think of it as a failing of their husband. When women do perceive men as inattentive to their wives' health problems it is usually attributed to concerns about money, rather than husbands' indifference. As one female respondent noted, "If someone ignores his wife then he does it simply because of want/poverty." Indeed, with few exceptions, men's objections to and lack of instrumental support for women's use of health services in the research sites usually concerned cost issues at some level. Many respondents reported that on the whole men have become more "conscious" in recent times and now give more importance to women's health problems than in the past, but there is often a disconnect between their concern or emotional support and their willingness (or ability) to pay. A husband told the interviewer that he is not happy about his wife going to the doctor, but only because he does not have the money to pay for the treatment. He used to be angry about her going out by herself but that is not the issue now, it is mainly that he does not want to spend what little money they have on his wife. Another man who was clearly not supportive of his wife during her illness commented,

"I cannot manage food properly so how will I manage the treatment of my wife? She has a father and brother - let them manage her treatment."

Reluctance to pay for women's health problems also seems to underlie some of men's ambivalence about contraceptive use. In the few cases where men objected to or disapproved of contraceptive use the apparent reasons often had to do with fears of side effect and related costs. Even benign, passive comments frequently made by men to their wives about family planning such as, "You adopt that which is best for you - your peace and happiness is your own responsibility" or " you manage your own affairs, it is up to you," may reflect attempts by men to avoid involvement and therefore responsibility in anticipation of negative consequences. One woman did not bother discussing her contraceptive use with her husband because even though he did not oppose it he had told her,

"I do not know [what to do] if something happens to you after adopting a method. I do not have any money. If something happens to you then I will not be able to do anything."

Another woman felt she could not ask her husband to get her pills after the program change because, even though he knows she is using family planning, he does not approve, again arguing that she should not use methods because he will not arrange or pay for treatment if the methods cause a problem with her health. Some women reported that their husbands get angry at them if side effects develop and blame them for taking the method, even if they had previously agreed to use family planning, implicitly if not explicitly. One woman cleverly dealt with this problem by sending her husband to the market for pills even though she knew she could get them from the clinic, which she would have preferred so she could discuss with the providers "various matters." 
She reasoned that if she got the pills herself this way her husband could blame her for any type of problem that developed but,

"As he is now providing me pills from the market, I can tell him about any kind of problem (side effect) and he will arrange treatment for me."

One male respondent attributed men's lack of financial support for their wives' health to a lack of understanding and a need for "family education," rather than real money concerns:

"Raising of the children in the family, protecting the health of everyone in the familythese are the real education. Those in the village who have passed the SSC or HSC lack such education. So there are many men who can buy saris and ornaments for their wives, but do not want to spend for their health and treatment."

In many cases women are ultimately not given sufficient money by their husbands for their health care, and often must resort to generating their own income to pay for services in the face of their husbands' explicit or passive resistance. One woman we interviewed sold a kilogram of rice to her sister-in-law in order to get money to go to the clinic when he procrastinated in bringing in medicine.

\section{Women's Mobility and Autonomy}

The requirements of the new program that women go out of the home to access service imposes a burden on some women because of time constraints and domestic responsibilities, rather than restrictions on mobility, per se. One depot holder reported that she knows of no women who are unable to go out of the house because of social restrictions. As in the urban sites, we did encounter varying degrees of limitations on women's mobility, but for the most part women (and men) were very matter of fact about the acceptability of women going out of the house to obtain family planning and health services. Although a few women reported being taunted en route to clinics, going to the clinic is considered "women's business" and a necessary part of life. In fact, respondents were virtually unanimous in saying that women's ability to travel outside of the home (if not the village) in order to avail themselves of health services is now a well-established norm within the community at large, if not within each individual household. Although purdah may still be regarded and pursued as an ideal, many people will not sacrifice much financially (or abandon fertility control) in order to maintain it. For example, the wife of a religious man tries to observe purdah but when the depot holder offered to give her contraceptive injections at home if she paid an additional 5 taka, she said there was no reason to pay extra for that.

Women also seem to have a remarkable degree of latitude to travel alone. To the extent that women in these sites felt they needed to have someone accompany them to clinics it was either because they had not been before and did not know the location, or because they wanted to have the support or advocacy of someone in dealing with the providers at the clinic itself (see discussion of the role of depot holders below). Concerns about the perceived impropriety of traveling to the clinic were rarely an issue. For example, one poor woman with 6 children had trouble leaving behind her domestic and childcare work to go get contraceptive injections at the NGO clinic and also did not want to go to there for the first time alone. (She had already traveled 
to the government hospital by herself but was turned away because she is living in an NGOdesignated area.) Her sister-in-law was too busy to go with her and her husband was always away all day looking for work (as a casual day laborer). During the course of her interview her husband implored the researcher,

"Apa, if I accompany her to the hospital, then I will not get any job from anywhere and have to pass the whole day with my children starving. I had an early marriage. She [his wife] can not talk properly at the clinic, as she is very young. It would be good if you write a slip for her so that they will give her injection".

Usually once women were familiar with the clinics the perceived need for an escort or advocate reduced substantially, though for other reasons (e.g., company, shared expenses) women may continue to prefer to travel together.

Respondents explained women's greater freedoms to travel outside for family planning and healthcare very much in terms of general progress and advancement in the communities overall. For example, one man explained that there is no objection to women going to clinics "nowadays" and that even newly married women can go alone because,

"Everybody is acquainted with the modern age - whether he is a maulana or a day laborer."

Individuals who do not subscribe to the new norms are considered backwards or illiterate, and these views are very often tied to what is perceived as the widely accepted imperative of fertility control. One woman explained her husband's willingness to let her travel outside:

"He does so because he is literate. Doesn't he know that if I don't go to the hospital, if I don't adopt a family planning method then I will have so many babies? We would face difficulties to maintain our family and bring them up properly. That is why he doesn't prevent me from going there...... Those who are illiterate don't understand these thingsthey resist their wives."

In addition to greater mobility and freedom to access healthcare outside of the home, increases in women's overall autonomy suggests that women's dependence on male acceptance and support in accessing family planning and clinics may be waning. Some of this increased autonomy may be due simply to the physical absence of men and the various roles women are forced to take on as a result. This situation seems to both foster independence among women as well as generate the social support and sanction necessary for women to perform these roles. For example, one respondent commented that nowadays no one minds if women go to the hospital because the men stay outside the whole day for their work and "the women have to do everything."

Men's employment in cities and outside the country may also contribute to women's autonomy by facilitating their greater control over cash. Women in this situation reported that they have to manage the family's finances when the husband is away, and they have blanket permission from their husbands to go out and get healthcare for themselves and their children when needed. Similarly, in one site there were a number of women whose husbands work in the Middle East 
and send remittances home in their names. To manage the money they had to go to the bank and were thus easily able to use the clinics in market areas.

The greatest area over which women seem to have developed autonomy is family planning use. Several women described their entitlement to make decisions about family planning relatively autonomously as a function of their unique burdens of childrearing. For example, one woman said that even if her husband forbade her she would use family planning because "the right (to take a method) is mine, because the responsibilities to bring up the children are mine." Another woman responded to her husband's objections that she was taking injectables even though she was sick by saying to him, "You realize your own problem, and I realize mine." She said that even if he forbade her she would not listen. She felt it is her right to make these decisions because "the sufferings I had undergone while I was pregnant were mine and not of my husband. So the right of adopting a method is also mine."

Similarly, some women seemed to gain (or achieve) autonomy in light of their husbands' passivity, resistance, or even their general inability to play a helpful, supportive role. This form of independence was very much a mixed blessing for these women as in most cases their lives would have been much easier had their husbands been able (and willing) to be more involved in a positive way. For example, several woman described making decisions on their own, often without even consulting their husbands, not necessarily because they wanted to, but because they felt their husbands had nothing to contribute to the decision:

"It was my decision [to use family planning]. My husband has no opinion about this matter..... know I need to acquire my methods myself because my husband does not notice these matters at all."

"My husband is a simple and little foolish person. There is nothing to talk with him about on this matter."

We also encountered a number of women who were using family planning fairly successfully without their husbands' knowledge. One woman had to try many different strategies to sustain contraceptive use after the program change because she had been using secretly. Her husband did not want to use family planning and did not allow her to go out of the house. She was willing to go out without his permission but when he stopped working and was home more frequently this became difficult. She took pills from her sister-in-law for a while and then switched to injectables since they required leaving the house to resupply less often. She was able to leave the house to obtain the method by telling her husband that she was going to visit her father who lived near the clinic.

Other women were forced to act on their own because their husbands were unable to be of any help:

"I know that my husband will never bring me to a doctor. It is not that he ignores me. In fact it is just that he is a very foolish person. The reason (he will never bring me) is that he will not be able to talk to the doctor." 
Similarly, one male respondent reported that his wife used to ask for permission and money from him to go to the clinic. When he stopped giving her money (because he thought he could not afford it) she stopped asking for permission. He said that earlier he would be angry and scold her if she used to go somewhere without permission but then he understood that "without financial strength nothing can be said." So he stopped protesting and now they do not discuss her health condition at all. When his wife lies on the bed and the household work is not done properly then he knows she is ill. He says he feels bad but "as a poor man I can do nothing." Another respondent noted, "Men of poor families stay less at home so how can they prevent their wives from going to the clinics for treatment?"

Indeed, when women perceive their husbands as having rights to make decisions about family planning and health matters it seemed to be based primarily on the expectation that he will pay for any treatment needed:

"The husband will decide about accepting a method, because in case of any problem, the husband will have to pay for treatment. Since he has the duty to look after (pay for) all the needs, the right to decide about family planning methods is also his."

Overall, the demands of the new program - requiring women to go out of the home to access health services, or to at least be more explicit about contraceptive use - are coinciding with a broader evolution linked to women's growing exposure and awareness, and to the economic imperatives that often prevail over traditional social norms. These trends allowing women greater autonomy in accessing healthcare may be forcing men to adapt. One male respondent reported that he was fairly ignorant of whether or not, when, and from where his wife took family planning methods. He was not in favor of using family planning but did not overtly object. When asked why he did not forbid his wife to use family planning since he did not approve, he responded that he understood from what she had said to him that she would take the method secretly even if he explicitly objected, "that is why I did not impose anything on her." The new latitude afforded women by men may also be in part a function of expediency and selfinterest. One respondent commented that in the past husbands wanted to control the movement of their wives. But now men do not want to do that because they think it will be easier for them if their wives can get their treatment anywhere by themselves. So men allow women to go to clinics and do not object if women go alone or with neighbors, and therefore "they (men) can avoid responsibility."

\section{The Role of Depot Holders in Facilitating Access to Services}

Although women were for the most part not constrained in accessing clinical services because of restrictions on mobility per se, many required, or at least preferred, to have the depot holder accompany them to the clinic or meet them there in order to introduce them or act on their behalf. In many cases women just wanted accompaniment to the clinic on the first visit since the place was unfamiliar to them. For example, one of the DHs reported that for the most part women do or at least can come to the clinic alone, but that in the beginning she brought them 
there since they did not know the place and felt shy to come on their own. One service provider remarked on the importance of the depot holder in bringing clients to the static clinic initially, noting that, "few patients come of their own accord." As described above, many women also reported feeling intimidated and uneasy talking to the providers and appreciated having the depot holder there to speak on their behalf. One woman reported that she could not have gone to the clinic for the first time without the depot holder, not because she could not physically move there alone, but because she felt shy to talk to the doctor. Some of women's hesitation appears to be related to perceived class differences (specifically education) and to expectations from experiences with providers elsewhere. One woman who wanted to ask questions during her clinic visit did not do so because she thought the provider is educated and therefore might mind. Another commented, "As we are literate, what will we ask?" However, again this feeling of intimidation seemed to often be a function of unfamiliarity and a number of women were in contrast quite assertive, "I will have to go for my own cause. If I feel shy then I have to die by sitting in the house. Feeling shame or becoming frightened is no more serious than to die. So there is nothing to be frightened or feeling shy."

In many cases the depot holder played an important role as an advocate for women. When women consult the DHs about family planning matters or other health concerns, they will often not only offer to escort the woman, but also to speak to the provider on her behalf in advance of her visit. Women seem to find this reassuring and in some cases appear to believe that this intervention had a positive impact on their clinic experience. For example, a woman who had decided to adopt an IUD under the new program declined the DH's offer to accompany her to the clinic, but she did ask that the DH be present at the clinic when she arrived to have the method inserted because she was afraid. The DH told her not to be afraid and that she would speak to the paramedics about her before she came. She also told her to mention the DH's name to the paramedic if she was not present at the time. The respondent had the IUD inserted at the clinic in the DH's absence and was satisfied. She reported that the "apas" had inserted her copper-t very carefully and had behaved very well with her. Another woman appealed to the DH to intervene after she felt like she was not getting good treatment. An NGO paramedic had attributed the woman's amenhorrea to her injectionables and told her to ignore it. The woman feared she was pregnant so she took the DH to see the paramedic to confirm it. She felt the paramedic had not "given any importance" to her complaint. She asked the DH repeatedly to get the paramedic to "see her with care." With the DH's involvement she did see the provider again (and found out that she was in fact three months pregnant).

\section{Access for Specific Populations}

\section{Newlyweds}

Ensuring that newly married couples are able to access services and initiate family planning under the new service delivery model is a priority concern of the NGOs. This concern is based on the assumption that younger, newly married couples may experience social constraints that limit their access to health and family planning information and services, and therefore specific, targeted outreach is needed. As noted above, depot holders do make newlyweds a focus of their 
outreach and the "newlywed couple meetings" that the NGOs organize are intended to reach both husbands and wives with family planning, pregnancy care, basic child health, and nutrition messages. We did find examples of women who had first learned about family planning through contact with health workers, but more commonly (and somewhat contrary to the expectation that without this contact women do not get such information) women heard about family planning and "vaccines" through mothers, mothers-in-law, sisters-in-law and, quite often, husbands. In fact we encountered several examples of husbands both taking the lead in initiating fertility control as well as actually obtaining methods and instructing their wives on how to use them.

We did find substantial gaps in knowledge as well as misconceptions among this subset of the community - about correct method use, safe periods and how to avoid pregnancy, and risks associated with contraceptive use - but they were by no means unique to this group (and, after all, the sources of many misconceptions are themselves in need of better information). The outreach efforts of the NGOs remain important, therefore, and our research confirms that people are very appreciative of the information that is provided. In addition to strengthening the coverage of these outreach activities (male attendance is particularly low), the NGOs need to sustain their focus on more than family planning issues and be sure that outreach efforts (such as selective visitation) do not inadvertently discourage women from coming out of the home to access clinics.

\section{Men}

Male use of the clinic services in these sites was fairly uncommon. Men (and women) associate the clinics with "women's diseases" and family planning (also a "woman's affair.") Some men also seem to be particularly reluctant to be seen by female providers - they would prefer to see male providers, or they think that female providers do not see men.

"This (clinic) has been built for women. That's why there are lady-doctors. If there were male doctors then the men would go there"

While men's hesitation is clearly reflective of their own assumptions, prior experiences (or lack thereof), and personal inhibitions, it is also a function of the historical marginalization of men in Bangladesh's family planning and $\mathrm{MCH}$ programs. It does not appear to be a function of an inherent lack of interest or sense of responsibility. The present program seeks explicitly to increase the involvement of men in reproductive health, but staff may need more training in how to integrate that goal into all aspects of their work, rather than just approaching men through occasional targeted outreach. For example, one depot holder reported that she does not provide information to men as part of her routine outreach because she was not taught in her training what types of services are available for men. Similarly, one man we interviewed went to the NGO static clinic in order to receive counseling about what kind of family planning method he and his wife should use. His wife did not come with him because she happened to be at her father's house at the time. The staff did not quite seem to know what to say to him and asked him questions about his wife. He left feeling like they would have preferred to talk to his wife instead. 
For a number of reasons it appears that more outreach to men would be beneficial. One respondent was asked what he thought were the main barriers to clinic use for women and he responded that in his village the women have more information about doctors and hospitals than the men do. Nobody prevents women from going to clinics but they do not always have money, and "all husbands are not the same - some do not give money to help their wives go to clinics." Another respondent (male) thought that the government or the NGO should make a rule that the husband and wife come together to the clinic, and this would improve the role of men. He reasoned that at first the men would not want to come, but if there were some opportunity available if they came together, such as free vitamins or discounted medicines, then the husbands would go.

\section{Working Women}

Among the women we interviewed very few were formally employed, but one woman who had a road construction job (as part of a CARE employment generation project) said that it was her sporadically employed husband who took their children to the NGO clinic for immunizations and health problems. The clinic was closed on her only day off. She used to go to the Thana Health Complex for her own health care but now her husband brings medicines for her from the pharmacy, or she ignores her problems. She worries about getting pregnant but she says that she stopped using the pill because it made her so dizzy that she fell down. She is afraid to use other methods and apparently has no source of information and counseling. While working women like her are a small minority in these sites, this is not the case in all rural areas, and it is quite clear that they are a special group with constrained access to basic reproductive and general health services.

\section{CLIENT SATISFACTION AND PERCEPTIONS OF QUALITY}

\section{Clinic Environment and Amenities}

There were many positive comments about the physical environment of the new NGO clinics compared to the past and to other facilities. People almost unanimously praised the clinics for being "neat and clean." They also appreciated the relative lack of noise or crowds. Even when the clinic was observed by the researcher to be untidy or slightly dirty, clients seem to regard this as excusable, and at least an improvement over other clinics. As one respondent noted,

"It is normal for village clinics ('hashpatal') to be unclean. The Apas are not responsible for the dirt. The clients carry the dirt with them to the clinic. These rooms are quite nice. Do you see the beautiful pictures of the mothers and children?"

Another woman who thought the clinic environment was good noted that it was a little noisy on the day of her visit but commented,

"I do not have any problem with the noise -- I need proper treatment." 
Some of the satellite clinic sites in the rural areas served by the NGOs present a real challenge for the service providers. The houses or rooms lent to them for this purpose are often small, dark and cramped, and may lack electricity, running water and toilets. It is often difficult to maintain privacy, but from what we observed the providers and clients mostly do their best to remain good-humored and accomplish their purpose.

In the permanent clinics, where more has been done to improve the physical environment, appreciation of this seems to vary with the socio-economic background of the client. Clients from economically stressed households seemed hardly to notice the clinic environment, whereas for better-off clients it can be very important. One client, for example, came from a large family who employed laborers to work on their land, and also had a hardware business. She used the NGO clinic for contraceptive injections, for which she paid only five taka, but she spent 40 taka on rickshaw fare to go there--70 taka in the rainy season. She felt that the NGO clinic was an appropriate place for her to go because it was small, pleasant and quiet, without a lot of people milling around, and because she was treated with courtesy. She said she thought of the service providers as her sisters, and she enjoyed interacting with other women in the waiting room. "It feels good to sit together with everyone and talk with them. I am meeting new people here," she explained. She would have felt threatened and insecure in a crowded public facility, she said--in fact, she might have chosen a different method of contraception if a government clinic were the only source for contraceptive injections.

People who had a chance to see educational films on the clinic television seemed both to enjoy and to learn from them. "Today I saw a television in the clinic which I had never seen before. I liked this! Because in the television many important things were showing from which people can learn many things."

\section{Convenience and Clinic Procedures}

Many respondents commented that proximity was very important for them, and this was why they valued the satellite clinics. These women were not prevented from going out to seek health care, but time and travel costs were a significant consideration for them. Some respondents found the infrequency of satellite clinics to be a problem and, because of this, did not rely on them for treatment of minor illnesses. A few women said they did wait for the satellite clinic if their problems were "not too troublesome" because the satellite clinic was cheaper and closer than other facilities, but families more often relied on other sources such as private doctors or non-accredited village practitioners because they were always available. Some of the comments were: "we do not see them (satellite clinic staff) in our time of need. They come with the interval of three months." "They do not come all the time. And we cannot sit idle when our children are ill." "The workers come every three months, but illnesses do not come at routine intervals." For contraceptives and immunizations the infrequency of the clinics was less of an issue.

People appreciate the operating hours of the static clinic compared with other places where the hours are shorter and the staff often shows up late. They also have modest expectations, and they sympathize with the female clinic staff, for example, "I could tell you that the clinic should be open from dawn to dusk, but would that happen? Could they stand the stress of working so long? A person needs to eat, to pray, to take rest." 
The NGO clinics were described as much less crowded than other places. Reported waiting times ranged from 5 to 30 minutes, and no one complained. Many respondents said they avoided government clinics because of the long waits. "Many people go to [the government clinic]," said one woman, "All types of treatments are available there, and money is not needed, but you have to stand in a queue and wait for about an hour in the sun, so many women go and get medicines from the doctor of the pharmacy instead."

The staff in the clinics and satellite clinics tried with varying effort and varying success to maintain an orderly system in which clients were given serial numbers and seen in turn. A few clients thought that those who knew the staff were given priority. One woman said, "They gave us a card with a number when the senior officials (actually, the researchers) came, but usually they do not do so." But in other cases, clients who tried to be seen out of turn were told, "whoever comes first will be seen first," and asked to wait. When it was feasible to maintain a "first-come first served" system, clients liked this, but they also tended to be quite tolerant when it broke down. For example, when large numbers of clients showed up at satellite clinics, many with noisy or sick children, procedures were sometimes modified in order to reduce the crowd and tend to clients as quickly and efficiently as possible; women seeking prenatal care or requiring a longer consultation were often asked to wait so that the children could be seen and sent home.

The physical spaces available for satellite clinics sometimes make it very difficult for the service providers to maintain order, especially when government EPI clinics are combined with the NGO's satellite clinics. This seemed to be a source of dissatisfaction only when the crowding and disorder became so extreme that women had difficulty being seen by the providers. One of the field researchers described the following scene:

"The crowd of women in the room increased when the EPI team arrived at 11:00 AM. The room was not very big, and much of the space was taken up by two cots on opposite sides of the room, adding to the congestion. There was only enough room for 4 or 5 women to stand between the two cots. With the two teams working in such close proximity, it was hard to tell which women were waiting for which. It was difficult to breath, and some women became agitated because of the crowding, and left the room without getting services...It was impossible for the paramedic to maintain a serial number system, so she did not even try, and she had no way of knowing who had come first. Those who were strong got served first by pushing the others aside...But it was clear that those who emerged from the room with medications in their hands were satisfied with the service they got."

Similarly, respondents reported that they often did not have privacy during their consultations, but few seemed to mind. In some cases the concept of a waiting room seemed to be a foreign one. Another of the field researchers described the experience of a client she observed and interviewed:

"She went towards the paramedic's room after talking to me. There were 4-5 other clients in the room at that time. She stood there with the others because there were not 
enough chairs. Each of the clients had a child with her. There was a waiting room but no one was sitting there. They all crowded into the paramedic's room where, on that day, there were four service providers (normally there would be two). Only the client consulting a paramedic had a chance to sit in a chair because the other four chairs were occupied by the service providers. One of the paramedics told the clients to go and sit in the waiting area, to stop crowding the room, but no one left. My respondent laughed and said, 'There is no problem, we will stand here."'

In the follow-up interview the woman said she did not know which was the waiting room because she always went straight to the paramedic's room. Then she looked around her and said, "This must be the waiting room. This is quite nice!" It was clean, light and comparatively cool, she noticed. When asked what she liked or disliked about the service providers, she said, "Their room is too small. There is too little space for $4-5$ women to sit there at the same time and this is annoying!" Asked why she didn't sit in the waiting room, she said, "This is a separate room. I came here with three other people. Why would I sit out here instead of going with them? The [paramedics] do not come out here. Only if I go in that room, will they notice me and ask me something. And in there I can hear what they say to the others. That is why I go there."

\section{Provider Behavior and Client-provider Interactions}

Respondents familiar with both NGO static and satellite clinics were overwhelmingly positive about the behavior of the providers. This was the aspect of the NGO services that was most consistently and earnestly praised. Women described the "apas" as speaking slowly and "in the same way we all speak in the village;" listening attentively and "for as long as the patient will tell;" smiling; not rushing; and not becoming angry. Many respondents emphasized the communication aspects of client-provider interactions -- they really seemed to value being listened to, asked questions, and being able to understand what the provider said. When they received explanations for procedures of the clinic or something related to their health complaint women also seemed to value this.

Again, women's appreciation of the NGO providers was often a reflection of their expectations from bad experiences in other facilities. Women described repeatedly how the government providers, "speak roughly," "do not like to listen to anything," and "show their temper." One woman said, "We cannot mention more than one [health] problem or they get angry." Although women recognized that the government providers were often rushed and overworked compared to the NGO staff, they often felt mistreated at government facilities and as a result felt afraid and hesitated to speak up for themselves, or even to ask simple questions. Clients in government facilities reported that the staff sometimes scolds or belittles clients when they inadvertently "say something wrong." This makes women afraid to go to these facilities without an intermediary to speak on their behalf.

Only infrequently were clients afraid to talk with the NGO clinic staff. One client explained that she did not ask any questions because the "doctor" was an educated woman (and she is poor and uneducated) so the "doctor" might be annoyed if she asked questions. A young woman went to the clinic and did not ask any questions because the "Apa might mind," but she explained that this was her first visit and speculated that if she went there a few more times she would have the 
courage to ask questions. She had understood every thing the "doctor" said because "the doctor spoke in our own way," she said.

An important aspect of client-provider interactions that emerged and often seemed to underlie positive impressions was respect. Women resent being shamed or belittled by providers, especially in front of other people. One woman described how at a government health facility she was publicly scolded by the provider for returning to the clinic complaining of side effects after she had already been told that her problems were due to not taking her pills regularly. The provider reprimanded her in front of other clients, "You have intercourse with your husband. But you do not take the pills. And again you come when you get into trouble. From now on you should take the pills regularly. If you do not take them regularly you will not come here again." The woman clearly needed better counseling or an alternative method--she was not taking her pills regularly because she thought they were causing her uncomfortable side effects.

One of the few women we interviewed who was unhappy with providers at the NGO clinics felt that, among other things, they were not treating her respectfully. She said she had gone to the clinic because she was experiencing pain during her pregnancy. She felt that her questions were being dismissed and that she did not get proper care:

"Apa, I asked them how my pressure is. They asked me why should I know this. Look Apa, am I illiterate that I do not understand this? They did not tell anything specifically about the condition of the child and what is the reason behind pain on that side of belly. I did not get anything from there. For this reason I do not want to go there."

When she asked them about her pains the Apas told her that she should not be afraid, as such pain is normal. She was asked to compare the quality of treatment to that at the government hospital nearby and she said,

"They take the patients seriously there but here [at the NGO clinic] they laugh at the patients. As when I asked them whether this time I would need stitches or not, as I had to have during my first delivery, they laughed at this. Look, Apa, is this a laughing matter?"

The above case was an exception, but it does suggest that the staff in NGO clinics occasionally need to be reminded that it is important to show respect for their clients. Joking can be a good way to build rapport, but the service providers should bear in mind that their attempts at levity may be misinterpreted by clients in a rural society where people of low socio-economic status in particular are not used to being treated with respect in health facilities.

In contrast, one very satisfied client of one of the NGO clinics seemed to really value the respectful treatment she received there, particularly because it was such a departure from what she was accustomed to. She had come to the clinic just to learn about it and maybe get some deworming tablets for her child. The paramedic explained to her about the clinic procedures and what services were available. In trying to understand the client's situation and needs, she asked the woman questions, including how many children she had and whether she was using any method of family planning. After learning that she was not, the paramedic started to counsel her about family planning. The woman had two children, and when she told the provider she was not 
using because she wanted another child the provider politely changed the subject. The client later said she liked the clinic especially because the "apas" were well behaved and gave her respect:

"Yes they really respected me. And the fact that the apas respected me should be something to be proud of. They showed respect, asked me about my problems."

About the family planning discussion she said,

"I liked it because the apas did not pressure ('jora juri') me to do anything. They urged me to take family planning but when I told them that I wanted another child they did not go any farther to stop me."

As with other aspects of quality, women often seemed more generous in their assessments than our field researchers were, based on their own observations of client-provider interactions. The women notice and really appreciate even the most basic courtesies and attention, and they seem to have low expectations. During one observation at a government facility, our researcher observed that the service provider was inattentive and distracted, and hardly paid any attention to his client. When she commented on this to the respondent the woman defended his behavior: "No, he was busy talking to someone else. He would see me after he was done with his other patient who was there before me. There is no problem." She described the staff of the FWC as caring toward the patients and pointed out,

"Didn't you notice that the dakter asked me whether he should give me tablets since he was out of ointments? He could have chosen not to give me the tablets as well."

Our overall sense from many different types of interviews is that people do not expect kindness or respect from health service providers. Among village practitioners compassion towards the poor is viewed as an individual trait and, as such, is highly valued. In government facilities, the staff are thought to be employed to perform certain functions, and if they show kindness or even common courtesy to their clients this is because of their own individual natures, not because this is expected or required of health staff. Here too, kindness, and even common decency is highly valued among clients. Some of the clients in the NGO clinics, by contrast, commented that the staff's good behavior towards them was intended to attract them - that they had to be nice in order to build up a clientele (the assumption probably being that the clinics would have to close down and they would lose their jobs if they failed to attract clients). This attitude may signal an emerging "consumer awareness" with regard to the use of health care facilities that, in the long run, could contribute to better quality of care by forcing providers to compete for clients as the number of health care options available in rural as well as urban areas increases. The NGOs are contributing to this potentially positive trend when they communicate to their staff the idea that their viability will depend on their ability to respond to clients' priorities, and when the staff convey the same concept to clients.

\section{Range of Services and Technical Capability of Staff}

Another very important aspect of client perceptions of quality and an important determinant of clinic use concerned the perceived technical competence of the providers and of the health 
facility overall. Some clients and potential clients of the NGO clinics seemed to understand the concepts of specialization and referral. They saw the NGO facilities as good, reliable sources for the essential services they are set up to provide, and they took advantage of the proximity of these facilities for their basic health care needs. In other cases, however, the focus on essential services provided by paramedics was seen as a sign of inferiority in contrast with higher level government facilities and some private practices. This view was particularly common in a research subsite where a government facility was not much farther away than the NGO clinicsuggesting that the location of the NGO clinics is a very important determinant both of their viability and their value in meeting unmet need for basic health care. People in this site had extensive experience with or knowledge of "senior" doctors in the area who are consulted for more serious ailments than what the NGO clinics are intended to treat. Many respondents reported that the NGO service providers were not qualified to provide treatment for serious or complex diseases (which they are not) and for some clients and potential clients this perception translated into a more general lack of confidence in the NGO clinics. They saw them as ill equipped to deliver even basic services. As one respondent opined,

"The doctors of [the NGO] are less experienced. They don't know how to treat a patient properly. Because they have less [medical training and professional] degrees...All the doctors of THC have MBBS degrees. That's why better treatment is available there for any disease. That's why everybody goes there."

The NGO clinics are also overwhelmingly associated with family planning and therefore assumed to be limited in their ability to provide other kinds of treatment; many people think the providers are less educated and only trained in family planning. Not inappropriately, they also understand that the staff in satellite clinics can provide more technical expertise than the depot holders can. One satellite clinic client said,

"Perhaps (the DH) does something with family planning. I have heard that she keeps the 'maya' pills. But I understand that she is not that much educated. She does not have any certificate. So I think it is better not to consult with her. If I take any method perhaps I will take it by talking to a certified doctor. Those who come to (the satellite clinic) are better than [the DH] as they have a certificate. [The DH] does not have a certificate."

Many respondents also equated the newness of the clinics and the youth of some of the staff with inexperience. One woman, comparing the NGO clinics to the government facilities said the latter can provide treatment for all types of complicated diseases since the doctors are experienced, but the NGO clinic cannot do this, since the doctors are new there and the hospital is new too. She expected that the NGO clinic would become better as it grows old. At the very least the providers are not yet "trustworthy" since they are new to the area. One respondent tried to explain why she believes people usually go to the THC for treatment:

"[The government] hospital is an old one. People are accustomed to go to [the government] hospital from earlier times. That's why most of them go there. [The NGO] hospital is a new one. And people usually have little trust/faith in a new thing. Besides, if a little mistake is done about the disease then it becomes a problem. Until now people 
don't have full faith in the treatment of [The NGO]. Maybe the treatment will be developed gradually. Then everyone will go there."

Some people also viewed NGO clinic as inferior because it caters to the poor and charges minimal fees. "How good could their treatments be? They are not highly qualified doctors; they are just ordinary doctors. They are the doctors of the poor people who don't have any money," said one middle class respondent.

Notwithstanding the perceived limitations of the NGO clinics in the study sites, there was considerable awareness of the need for essential preventive services such as child immunization and family planning in the study sites, and the NGO clinics and satellite clinics were fairly well recognized as sources for these services. An increase in awareness of what was available from the NGO clinics was evident from one round of data collection to the next, and it was apparent that the NGOs were using a variety of strategies to "get the word out," some more effectively than others. Many of the women interviewed were acquiring a new appreciation of the importance of prenatal care and maternal nutrition, apparently as a result of the NGO community-based education activities. They seemed very pleased when the service providers talked with them about nutrition and hygiene. Many commented that this was valuable information and that they were learning many things they did not know before about how to protect their families' health.

The concept of "one-stop shopping" may have limited applicability for people seeking basic preventive services, especially in satellite clinics, unless it simply means getting contraceptives and an immunization for the child in the same visit. Several respondents pointed out that health needs often do not coincide in time. Cost recovery potential from these services alone is also limited because most people are not willing to pay much for these services.

\section{Drugs and Treatment Outcomes}

For many clients the perceived outcome of any treatment provided in a health facility is the primary criterion by which quality of care is judged. A client may not return to a facility if her, or her child's, presenting problem is not resolved, and her proclivity to recommend the clinic to others also depends on whether a treatment was thought to be effective. It should be noted that this standard for assessing and choosing health care facilities developed in the context of a weak and over-burdened public health care system in which client-provider interactions are often minimal and typically revolve around the dispensing (or failure to dispense) subsidized medicines. Thus, the success or failure of an encounter with the health care system from a client's perspective is often assessed by whether medicine(s) were provided, provided in seemingly adequate quantities, provided for free, and whether they were "effective" or appropriate for the problem. The latter is judged later, depending on whether the symptoms subside. The following descriptions of the researchers and comments from clients of government facilities are typical: 
"Although there was a stool next to the paramedic for clients, no one felt it necessary to sit there. All the women were talking about their problems and the paramedic was giving out medicine accordingly. I saw [the client I was interviewing] standing beside the paramedic and telling her something. Without looking at the client, the paramedic gave her some tablets wrapped in paper and said something to her. ... Within a minute [the client] emerged from the room smiling, and came over to talk with me.... Sometimes she had to return from the clinic without medicine, and often they gave very few pills but today she got more so she was happy. 'The medicine of this clinic is very effective. We get good results from taking it. But there is a problem here. The [staff] do not come regularly and they do not provide the medicine properly' she explained, 'We hear that they sell the good medicines. They used to provide a whole packet of medicine for children's fever and cough but now they divide it among five people.' She explained the irregular attendance of the staff by saying, 'They will have to provide medicine if they came and if they came every day their supply would run short.",

"She said that sometimes after waiting in line for an hour they tell her to come another day as the medicine is finished. Besides this, she has noticed that they give the same kind of tablet for fever, dizziness, and body pain. She thinks that they should give different types of medicines for different diseases...She told me that the doctors sold the good medicine outside the clinic, and when I asked her why she thought so she said that illnesses were not cured with the medicine they gave out.... I asked her whether she has ever said anything to the doctor [about the type of medicine she is given] she said 'Do we have such prestige that we could go to the hospital and start a quarrel with the doctor? Anyway, I'm afraid. The medicine that we get is beneficial for us. They may not give us any medicine if we quarrel with them."'

In other words, for many people in these communities a "good" clinic is one where diseases are cured, usually with medicine. When asked about her experience at the NGO clinic, one recent client said the 'Apas' are well-mannered and the hospital is clean and she likes this but she complained that she did recover from her vaginal discharge problem, "when a hospital can cure an illness then that hospital is a good hospital and I would also say good things about that hospital to others. I went there (NGO clinic) because I had heard that the hospital was good. Maybe the hospital is good, but I did not recover from my problems." Sometimes people will say based on one bad outcome that they will not go back at all, others say that they might go back, but not for that specific complaint (though the latter may just be said for the benefit of the researcher).

One woman was clearly frustrated by the NGO providers' response to her ongoing problems with contraceptive side effects and what she perceived as incompetent treatment. When she first complained to the DH she was told to continue and that the problem would go away. She stopped taking pills and at the suggestion of a market doctor asked for injectables after explaining her problems to the NGO providers. She was frustrated by their response, "There is no use in telling lies about them," she said, "They advised me to take two glasses of water after taking pills." They told her based on an examination that the injectable was not appropriate for her and suggested she take an IUD instead. Later when she complained again they gave her the same suggestions and she was unsatisfied, wanting instead medicine or a prescription. 
In fact, the perceived skills of the provider and treatment quality were described by several respondents as paramount considerations and they were clearly willing to trade off "nice behavior" (something they very much appreciated) for what they expected to be more reliable treatment. Several women noted that although they were satisfied with the providers' behavior, what matters is quality of the treatment, not the behavior. "A patient will not recover merely from the behavior of the doctors." Another woman remarked, "The apas are extremely well mannered - they listen to their clients very carefully. The only problem is that they are not big doctors."

Several people were asked directly if they would rather go to a "big doctor" who behaved rudely towards them, or a "little doctor" whose manner was very nice. The responses were mixed, and in one or two cases contradictory, suggesting that people are not used to making such comparisons. Other statements suggest that this would depend on the perceived seriousness of the problem.

One respondent did not have a successful outcome from the treatment she received the first time she went to the NGO clinic. She was highly satisfied with several aspects of the clinic - the providers, the proximity and convenience, and the cost - and was very aware of these benefits relative to other places, but in the end the quality of the treatment would determine where she would go in the future:

"Look apa, if I go to the THC then I will have to pay 10 taka rickshaw fare. It will take time to reach there and I will have to wait there a long time and then I will get the treatment. If I go to [the NGO clinic] it will take less time to reach there. I will not have to wait. They will give me a prescription for 5 taka and I will buy the necessary medicine outside. I am happy with this system [of the NGO] but they will have to provide good treatment."

\section{Referrals}

Interestingly, respondents had somewhat mixed feelings about the referral systems of the NGO clinics and varying interpretations of what it implied about the technical competence of the staff. Some people clearly felt positive about it and seemed to understand that the clinic was intended to facilitate access to other services and that referrals to higher levels of care were an integral part of the services they provided. One woman thought the system actually reflected the NGO's commitment to the community,

"I always come here. They give treatment for all types of disease and if they fail they tell to go to other places... They are caring. If one medicine is not effective then they give other medicines. They try to do their best. They will refer to [a government facility] if they fail. They do this as they have love for us."

Another respondent who had faith in this system said: "I like this because if they cannot diagnose the disease and if they think that we will not be cured by their treatments then they send 
the patients to the senior doctors of the THC." However, others took it as an indication of the NGO's limited qualifications,

"[The NGO] checks up the patient and if they can't do it then they send them to [a private provider], or to (a government facility) after writing a card. So how experienced can these doctors be? They are hardly qualified."

It is common for rural people to use intermediaries such as family planning workers and village doctors to get access to services and a presumed higher standard of care from health facilities that are unknown, and assumed to be indifferent to the plights of powerless would-be clients who are too ignorant to understand how they operate. Thus, there is a longstanding tradition of referrals for health care. This common practice could be highlighted in trying to spread the idea that the NGO clinics are meant to address a limited range of basic health needs for which the staff are well trained, and that they are also well trained in recognizing when referrals are needed and in making appropriate referrals - in other words, that they are dependable, and that they can help clients to save time and money by directing them to appropriate sources of care.

\section{Female Providers}

Many women commented that one of the major advantages of the NGO clinics is the availability of female providers. Usually women said they prefer female providers because of greater comfort talking to them compared to male doctors, either because their health concerns are "women's diseases" such as reproductive health complaints or contraceptive side effects about which it is "not possible to talk freely with a male doctor," or because they simply find it harder to talk to men: "We have to know how to talk as we will say one thing but they (male doctors) will understand another thing. So how will the disease become cure with this?" A few women were also happy to have female providers available because they anticipated less social objection to their clinic use if the provider is a woman:

"Everybody would take it in a negative sense if I were to go to a male doctor for treatment being a woman."

Only one (female) respondent conveyed a negative attitude about the female providers of the NGO clinic and this, again, was related to perceived technical competence. She was going to the satellite clinic regularly to receive her injectables and was asked by the researcher why she did not go there for other types of healthcare:

"I do not go there because they (the providers) are women - how much do they know and what treatment can they give us? But [the private doctor] is well educated and knows so many things. How much have those Apas studied?"

Although, as noted above, the lack of male staff was cited as a reason for men's low service utilization, we did interview men who had been to the clinic for their own healthcare and were satisfied by the treatment they received from the female providers. One man who commented that men do not use the clinic because of the female staff said of his own experience that they "examined with much care for a long time" and he was satisfied. 


\section{Social Equity}

Most respondents familiar with either the static and satellite NGO facilities said that the NGOs provide services and comparable treatment to the poor and the rich alike. This opinion was shared by respondents of various socioeconomic strata. One woman explained that the Apas take money from all, so they give equal treatment to all. The perception of social equity on the NGO clinics is notable in light of the widely held belief (documented abundantly in both this study as well as other research) that only the well-off or well-connected are able to access quality services and courteous treatment in health facilities. As noted above, where social distance was perceived or anticipated at the NGO clinics it was for the most part not attributable to behaviors of the NGO staff as reported by respondents or observed by our researchers. For example, one woman who thought that the medicines she received from the NGO clinic were ineffective assumed she had been given poor treatment, and thought she was being taken advantage of as a poor person,

"There are MBBS doctors clinic (implying: capable of prescribing good medicine) in the (NGO) but they do not give us the good medicine; they give to some, otherwise they will get caught, but only to those who are acquainted with them. But we would never be able to say anything (because we are poor)."

Similarly, another complaint about differential treatment at one of the NGO clinics was really a general comment about the lack of good care for the poor anywhere,

"When I go to the medical they do not care about me as I am a poor person and for this reason they do not give me the medicine. But if the rich people go there they give them the medicine with honor... all medical are the same."

Tolerance of or indifference to social inequity and prejudice may also be a reflection of people's low standards and expectations. For example, one of our researchers observed an exchange between a paramedic and the mother-in-law of a woman who had come to a government clinic for family planning in which the paramedic asked, "Why did you get your son married to such a dark girl?" Both the mother-in-law and the young women appeared to be made uncomfortable by the remark, but later reported that they were satisfied with the clinic, including the "apa's behavior."

\section{Waiving Fees for Those in Need}

Many people believe that the poor should receive discounted or free health services, and that providing these services for the poor is the government's role. But often because of shortages, poor management or corruption, people who seek subsidized services at public facilities go away empty handed. In other cases subsidies in private as well as public facilities are given only after providers yield to persuasion and grant special favors. In this context, people often view the provision of subsidies as an aspect of service quality, and the very poor often see this as the most important aspect. One woman had gone to the NGO clinic, where she was unable to pay the consultation fee, and she left without a medication that she said the paramedic had prescribed for her contraceptive side effects because she had no money to pay for it. Then she went to a 
government clinic and got the medication for free. Asked about her experiences at the two facilities, she commented:

"The apas [at the government clinic] spoke to me angrily. But medicines are available there at no cost. It is better. The apas of the [NGO] behave nicely, but they do not give medicine or treatment without money. It is very good for me if I get treatment and medicine at no cost, even if I am scolded...The [government] hospital is better in every aspect. But the behavior of the doctors is very rough. But so what if the behavior is bad? Good treatment can be gotten from there. Medicines can be gotten without any money. The behavior of the apas of the [NGO] is good. But what would be the benefit of good behavior if I do not get anything without money?"

Respondents criticized the clinics for not showing enough special consideration for the poor and apparently insisting on payment of what were considered trivial amounts of money from the provider's perspective. One woman complained that since the pricing was the same for the rich and the poor, the poor had no "special place" at the clinic. She seemed to feel that the charges were fairly reasonable, but that in principle the poor should always be charged slightly less. But she seemed particularly critical of the practice of requiring repayment of credit given for 1 or 2 taka. She said that she liked the clinic, but when the provider told to pay the remaining balance of 1-2 taka later she felt very bad. She said that if 4 or 5 taka was outstanding it would be all right for them to request it be paid later but it was not proper to charge 1-2 taka on credit. Even shopkeepers waive 1-2 taka without much thought, she argued. She said that in the case of people unable to pay, the clinic could waive the payment of such small amounts very easily, but they do not do so. "They take the 4 taka (leaving 1 taka outstanding) and tell the patient to pay it later or they will be responsible to Allah." Another woman commented, "the apas are nice but they should not take the little arrears such as 1-2 taka from the patients. As this hospital is "halfgovernment" (adha sharkari) they can write this little arrears in the government portion of the account. But instead they collect even one taka."

It is clear that for the very poor cost is inseparable from quality, and what matters is whether free services and commodities are available. But the way in which subsidies are given and discussed is also an important part of service quality for many clients - whether discounts and free services are given fairly, whether service providers show empathy and compassion for their clients, and whether they treat them respectfully when they do not have enough money to pay for services. One woman we interviewed received a prescription from a paramedic at the NGO clinic but then could not purchase the medicine because she did not have any money with her. Nevertheless she was extremely satisfied with her clinic visit because she felt that the providers trusted her and behaved respectfully:

"Even though I was empty handed, they did not turn me away. They knew that I did not know about the money (that it was needed), but still they showed their good behavior. They did not turn me away."

Several respondents reported that they felt ashamed when they came to the clinic, received treatment, but then did not have the money that was asked of them for services charges or medicine because they did not know in advance that money was required. Most of these were 
women who could afford to pay for the services and would have brought money if they had known.

Ambiguity about payment can cause confusion and sometimes discord. Most of the clinic clients we interviewed either could not, or did not, read the signs listing service charges. (Even if they had they would not have known that discounts and credit were available for those who needed it, nor how the need for credit or subsidies would be judged). In most cases payment is requested only after a service is provided, and most women said they preferred this. (Asking for payment at the end of the consultation is also consistent with the NGOs' policy that no one be denied treatment because they cannot pay.) But some women objected to this system when they then felt that it put them in an awkward position (perhaps they could afford the service pay but they might have gone elsewhere if they had known they would have to pay). One woman had a negative experience of bargaining with the providers when she refused to pay what was asked of her because she did not want to spend all of the money she had with her on her treatment. She felt strongly that the charges should be explained clearly in advance of treatment so that women can choose whether they want to take the services or not.

Other women, in contrast, appreciate subtlety in interactions around payment; they find it distasteful to have to discuss these matters explicitly. One woman was very pleased that the providers never had to ask for money from her; now that she knew how much to pay for injectables she was always able to pay them before they needed to say anything:

"It is embarrassing if they ask for taka from someone. For this reason they inform in the beginning that for the injection 5 taka will be required. Then we bring the money accordingly. If they were always asking for taka immediately when the patients go there then the patients would feel embarrassed."

\section{PAYING FOR SERVICES}

The NGOs'success in expanding the use of basic health services in the rural communities they are seeking to serve, and to recover some portion of their costs, will depend both on the ability and on the willingness of potential clients to access and pay for the services. Ability to access services may be influenced by distance, knowledge of the services and social constraints as well as prices. The NGOs have developed strategies to mitigate all of these potential constraints: satellite clinics, a variety of communication efforts, targeted home visits, and need-based subsidies, among others. Willingness to pay depends not only on how much the services are valued by clients, but also on clients' attitudes regarding the legitimacy and appropriateness of the charges. Education and an emphasis on service quality may increase the perceived value of the services to clients. It is certainly possible to influence the way people view the appropriateness and legitimacy of service charges through information and communication, but this is not necessarily an easy or straightforward task. Such attitudes are influenced by the service delivery approaches of the past, as well as confusion about how the present program is a departure from that model. They reflect assumptions based on prior experiences with a variety of service providers, experiences that vary among individuals and communities depending on their exposure to various types of providers and standards of care. 
The majority of respondents felt that the amounts charged at the NGO clinics were fair and not prohibitive, especially relative to the charges at other facilities for comparable services (e.g., government doctors engaged in private practice after hours and other private practitioners). But several widespread ideas that were articulated in a variety of different types of interviews and informal discussions are clearly influencing willingness to pay for the services in the NGO clinics; these include, (1) that good quality health care is usually available only if one has the economic means to purchase it, either from private providers or from government providers operating private practices, and that the poor therefore lack access to it; (2) that government has a responsibility to the poor, and that health and family planning services provided by the government should be free; and (3) that health service providers should show compassion and help economically disadvantaged people meet their health needs, especially if they are personally acquainted with them.

\section{The Plight of the Poor}

The data on health care decision-making suggest that the poor are used to sacrificing considerable time and effort to get health services free or at the lowest possible cost; thus, they may travel long distances, often on foot, undergo long waits in crowded government facilities, and go to a variety of different places for different health needs in order to get the lowest prices. Or they may simply let a disease run its course because they lack money for treatment.

There is a general expectation that good medical care requires money and that the poor will naturally therefore often lack access to healthcare, both in the NGO clinics and more generally:

"Actually there is nothing for the poor. Everything is for the rich. Everywhere requires money. Treatment would not be availed without money anywhere."

"Many people need to go to the hospital but don't. They sit and wait for their diseases to get worse. The words of us poor people do not have any value. No one would listen to us if we go to the hospital without any money."

\section{Expectations of Government and Confusion about the Status of NGOs}

Many people believe that the poor are entitled to receive free health services, particularly in government facilities, and the poor tend to see the government as their health care provider of last resort. Low income respondents in the study areas described many limitations of the government health system, but they also made it clear that they were grateful to have health facilities where they could get some free or nominally priced health care even if obtaining it was not easy or pleasant.

The expectation that government services in particular should be free, coupled with widespread confusion about the relationship between government and NGO services leads some to resent or even be suspicious about the NGOs' service charges. Many assume that the latter are in fact government services, or they are aware that NGO services are publicly subsidized. As a result, the majority of objections to the service charges we encountered were related to perceptions that 
the services were in some way government provided and therefore should be free. One woman who was very satisfied with the service providers' behavior and was even offered credit nevertheless said she would not go back nor tell others to go to the clinic because of the charge since she assumed the staff worked for the government and received a salary. Another woman was allowed to take credit for the 5 taka service charge but intentionally declined to repay it, arguing that the service providers could afford to lose the taka since the government is giving them money. Others perceived the NGO charges to be so inappropriate (because they were assumed to be GOB funded) that they opted to pay more elsewhere instead out of protest.

This reluctance to pay is not new to the NGOs. Similar objections were raised when they introduced nominal charges for contraceptives under the doorstep program. Then clients often protested or even refused to pay for methods, believing they were supplied by the government, and depot holders in these sites reported having to hassle clients often and even paying for the supplies out of their own pockets when they were unable to collect money. However, once clients understood clearly the purpose of the charges and believed that they were being collected for legitimate reasons, most came around and were willing to pay, at least what they could.

Similarly, under the new program, once people understand that the NGO services are not part of the government they tend to think the charges are appropriate, as well as reasonable. One woman stated explicitly that as the NGO clinic was a "company's hospital" and naturally had many expenditures to cover, the service charges were ok, "but we become dissatisfied if the government hospital takes taka, as the government is supposed to manage free treatment for poor people in the hospital," she said. Another woman initially thought it was absurd that the NGO was charging but once it was explained to her that the staff were not government employees she thought that both the fact that they charged and the amount they asked for were fine.

Confusion between the government and NGOs may be perpetuated by the use of the Green Umbrella logo at clinics. A number of respondents commented on what they perceived as a discrepancy between the advertising on television and radio associated with "Shobuj Chata" and what they encountered in the NGO clinics:

"I have heard from the TV that Green Umbrella Hospital gives services for the poor. But money is charged at [the NGO]. But is it never told in TV and radio that money will be charged here. Since [the NGO] is Green Umbrella Hospital, it is for the poor, but they charge money. I asked the apa why do they charge money?"

Joint satellite with government health staff may also be giving the impression that the NGOs are actually part of the government.

Although many respondents convey a sense of resignation (implying that the poor are underserved and little can be done to alter this), well-off and poor people alike also expressed feelings of injustice, typically focused on the government, which they saw as failing to fulfill its responsibility to the poor. One respondent was clearly resentful and angry about what she perceived as a failure to provide services to the poor at the NGO clinic, but her feelings seemed to stem from a sense of entitlement vis-a-vis the government, as well as confusion about the role of the government in the NGO program: 
"Nothing is provided for the poor people like us...everywhere charges, including [the $N G O]$. Has the government told them to take this charge? Doesn't the government pay them a salary?"

\title{
Expecting Free Treatment for Side Effects
}

In addition to being seen as a health care provider of last resort, the government is viewed as having a population control agenda. Thus, when women adopt contraceptives, even though they do so for their own benefit, they feel that that they are doing this at the government's behest, and that the government should shield them from any negative repercussions. To many women therefore, it seems only right that treatment for side effects should be provided free. An example of such reasoning is a woman who went to one of the NGO clinics to seek for side effects from her contraceptive injection. She was given oral pills and charged for them. This did not solve the problem, and she was unhappy about that, but she was also angry about the charges:

"If I want medicines for my menstruation which stopped because of taking the injection, they want money at (the NGO) clinic. Are they not supposed to give medicines free? It had to do with the injection.... They built a hospital. If it is necessary to pay money at the hospital what would us poor people gain from it? I have to pay money even for a single pill."

Another woman complained,

"It was the same when I used to take pills (oral contraceptives). Then also apas would say that they would give medicine for the physical weakness, but only if I paid for it. I say that if we have to give money, we should take it from [a private] doctor."

In other words, according to this woman, why should women pay this money to the people whose job it is to get them to accept family planning?

\begin{abstract}
Ability to Pay
The researchers reviewed transcripts from 112 interviews with recent clients of the rural NGO clinics and satellite clinics, and sorted them into three groups: (1) clients who had no apparent problem paying; (2) clients who were able to pay but needed credit because they did not have enough money with them when they went to the clinic; (3) clients who appeared to need a subsidy. ${ }^{2}$ The results are shown in Table 2.
\end{abstract}

\footnotetext{
${ }^{2}$ We classified women who received credit or subsidies as needing them unless there was clear evidence to the contrary. Therefore this analysis would overstate the need for credit or subsidies if they are being given when they are not actually needed and if this was not clear from the interview. The table may also understate the number needing and receiving credit as opposed to subsidies, insofar as the clinic staff provide subsidies in the guise of credit.
} 
Table 2. Clinic Clients' Needs for Credit and Subsidies

\begin{tabular}{lccc}
\hline Site & Able to Pay & Needed Credit & Needed Subsidy \\
\hline & & & 15 \\
Chandpur & 24 & 18 & 13 \\
Kishoreganj & 23 & 19 & \\
\hline
\end{tabular}

The results show that about $42 \%$ (47) had no problem paying on the day they most recently visited the clinic. About a third (37) needed credit and, of those, 29 received it. A quarter of the clients (28) needed a subsidy, and 21 received free or partially subsidized services. In some cases it was difficult for us to ascertain whether a client was given a subsidy, because subsidies are sometimes disguised as credit (see footnote). Subsidies and credit were often given for services and contraceptives but rarely for medications.

We know that in at least a few cases women who needed credit or subsidies failed to make this known to the service providers, but as this was not always asked in the interview, we are unable to specify the number. On the whole, these findings imply that the current prices were within reach of the majority of this small sample of clients, but that many clients need credit and a substantial minority needs subsidies.

Among the women who needed either subsidies or credit, very few, if any, left a clinic without receiving any service whatsoever, but some were unable to avail themselves of the full range of services that they might have needed. Usually it was medications or lab tests that they could not obtain. A few women were sent home to get money.

A similar analysis of interview transcripts from 15 clients of depot holders suggests that the need for credit is substantial-more so than in the clinics (Table 3). As more than one depot holder told us that she had dropped clients who could not or would not pay, this set of interviews would not be useful for assessing the need for subsidies among women using oral contraceptives, but several women did tell us they had walked to government facilities and lied about the name of their village because they were desperate to get oral contraceptives for free and they had heard that the government clinics were turned away other women from their village and told them to get contraceptives from the NGO.

Table 3. Depot Holders' Clients' Needs for Credit and Subsidies

\begin{tabular}{lccc}
\hline Site & Able to Pay & Needed Credit & Needed Subsidy \\
\hline Chandpur & 2 & 8 & - \\
Kishoreganj & 4 & 1 & -
\end{tabular}

\section{Need-based Subsidies}

In the new NGO service delivery model, need-based subsidies are intended to mitigate gender and class-based constraints to paying for services. The NGO clinics have a policy that no one should be denied services because they cannot pay, and many clients do receive discounts. The clinic staff finds it difficult to provide these subsidies openly and systematically, however. They 
fear that openly waiving or adjusting fees for some would raise concerns about fairness, and make it difficult to enforce the posted prices for the majority of clients. Service providers said they often gave free services by telling the client to pay the balance later, and writing an amount is owed on her receipt. They did this both to avoid embarrassing the client and to avoid advertising the availability of subsidies. Thus despite the NGOs' official policy of providing subsidies, subsidies are not given transparently nor systematically.

Clinic staff are trying conscientiously to identify clients in need and to provide them with services, but they also understand that cost recovery is a priority under the new program and they are trying to reconcile these two mandates. In most cases they discuss payment in very delicate ways, in order to avoid offending or embarrassing the client, and in most cases they are kind to clients who are unable to pay. They try to direct subsidies to clients who really needed them. A well-dressed woman whose husband worked abroad, for example, was told, "Apa, this [free] medicine [contraceptive injection] is for those who do not have the ability to pay for it. Your husband lives abroad [implying that he earns a good income] so we should not give it to you, but we have." She probably hoped that the woman would understand and reimburse the clinic later. Another paramedic was heard saying to a woman who did not realize she would have to pay for an antenatal check-up: "You can pay the money later. Today you should have the check-up. You need this." A paramedic in a SC seemed genuinely distressed because she apparently had been instructed not to provide medications for free, but she could tell that the extremely poor woman to whom she had given a prescription for a vaginal infection would not be able to purchase the medication. She gave her a couple of cheaper free medications for other problems and showed a lot of sympathy for her, but she apparently thought she was not authorized to give the medication the woman needed without payment.

The clinic staff were virtually unanimous in saying that it would be a mistake to make the existence of discounts widely known. A paramedic in one of the clinics explained that although they had been instructed that no one should leave the clinic for lack of money, they always tell people to pay later. "If we provide free service to someone then others will also demand it. It may create a disturbance," she said. Asked whether information about the availability of credit, discounts and free services was mentioned on the posted list of charges, she said that it was not, and if it was, no one would want to pay. As to whether she thought that people in the surrounding communities knew, and whether they should know, that these things were available she said that people generally did not and should not know. As virtually everyone in these villages is poor, then it would be very difficult to justify giving subsidies to some but not to others, and it would only cause trouble.

The failure to advertise the fact that subsidies are available in the NGO clinics may be creating hidden problems. First, the NGOs may be perceived by some as overly concerned with cost recovery and not concerned with the welfare of the poor. Although most people reported that the NGO clinics were accessible to and used by poor and rich alike, a few commented that because the NGO charges for services it is mainly serving the better off: "Those who have taka and are rich go to [the NGO clinic]," said one respondent. Second, clients may not take advantage of "one stop shopping" because they cannot afford everything they need, or they may not return to the clinic for fear that they will be asked to pay the remaining balance from the previous visit. Third, clients may "self-select" -in other words, they may not go to the NGO clinic at all 
because they think they will not be able to afford the service charges. Aware of this possibility, NGO staff have modified the promotional messages that they spread in the communities they serve; they have started telling people that the clinics charge for services but that people should come - they should not avoid coming to the clinic just because of money. But how are people to understand this ambiguous message? If it is meant to clearly communicate the availability of need-based subsidies, then why not make it clearer? Are the NGOs hoping that only those genuinely in need will understand it?

It may not always be apparent when a client needs a subsidy. People in need of subsidies may not ask for them, probably for a combination of reasons: shame, assumptions based on previous experiences elsewhere, and lack of information about the availability of subsidies. Our field research team felt that in many cases the slightly better off among the poor tended to be more self-confident and were more likely to bargain or ask for discounted fees compared with the very poor, but this observation is based on informal impressions and we do not have data to substantiate it. A substantial number of respondents told the interviewers that it was not possible to bargain or to get services, family planning methods or medications at reduced prices in the new clinics (while many others did receive credit or subsidies) but we are unable to classify these people by economic level, at least not with a comfortable level of certainty.

We encountered several reports of individuals not using the NGO clinics because of cost considerations, either because they knew or assumed they would not be able to afford the charges, or because they did not know they could receive a discount and/or felt inhibited from asking for one. One of several destitute women who knew of the NGO clinic but did not use it because of concerns about money said,

"We have heard that one strip of pills costs two takas [there]. Instead of paying them the two takas, we could spend the two takas to buy something for the children, and feed them. We will walk to [the THC] in order to get [contraceptive] methods even if it is a problem."

Many women incur inconvenience and discomfort to save money. One woman who was unable to pay for the advantage of the proximity of the NGO clinic walked a substantial distance to access free services at a government facility. "I think even if it is harder, still I have to get it from the [government] hospital. And since I walk, there is no rickshaw fare." she explained. Another women had been to the NGO clinic complaining of side effects related to the pill. She was given a prescription by the paramedic for "medicine" which was available at the NGO clinic for 65 taka. The client felt she could not afford either the medicine or the service charge and she left without paying, feeling ashamed that she had received the treatment (the consultation) and then not been able to pay. When she then went to the government hospital for this problem she was treated very rudely by the providers but she did receive tablets for free. The fact that these women are going to such additional trouble to access free family planning and healthcare plainly shows that subsidies are necessary for them. Unless and until they are able to access subsidized services from the NGOs, the safety net of government facilities should not be cut off.

The women described above were able to obtain the health care services that they needed, but others may not be so resourceful or persistent. The NGOs can avoid turning people who cannot 
pay away from clinic by making it a policy to serve them free of cost, but it is more difficult for them to accommodate people who do not seek out or ask for the services they need. A woman who had been suffering for a long time from vaginitis felt she needed treatment but did not go to either the NGO clinic or to other facilities. She knew about them, but she felt she could not afford the service charges and did not think she would be able to get a discount. Other women said they felt uncomfortable asking for credit or discounts and either did not go to the NGO clinics, or left without getting everything they needed. One woman could not afford three taka for a contraceptive injection at the NGO clinic but said she felt too intimidated to tell the paramedic (whom she perceived as "rich") that she could not pay for it. She wanted to bring the depot holder with her to explain her financial situation on her behalf.

The data suggest that knowledge about the payment requirements has improved over time in the study communities, but we found little evidence that knowledge of availability of discounts was improving.

\section{Credit}

Respondents reported that under the doorstep program credit for contraceptives was readily available and that is was a considerable advantage of the door-to-door services. Women had most often developed personalized relationships with the family planning worker and felt they were neither denied credit when they needed it, nor pressured unduly to repay their debts. Under the new program, the availability of credit seems to vary and be evolving over time. On the one hand, the women who chose or were forced to switch to pharmacies as their supply source after the transition lost access to credit for contraceptives for the most part, and for some this was perceived as a major disadvantage of the new system (as they experienced it). Other women who began obtaining methods from the newly established depot holders had uneven access to credit, often depending on the will of the individual depot holder. Some became less willing to provide supplies on credit as their income under the new system was more dependent on their portion of the revenue from sales of contraceptives and basic medicines; they were less eager to assume debts for potentially "bad risks." Women who obtained family planning and health services from the NGO clinic facilities were for the most part denied credit in the early stages of the program, but over time it has become more available as the clients have became more familiar to the providers. Early on in the program the lack of credit was perceived by one of the depot holders as a major reason for the low number of clients at the clinic,

"As people have to pay cash for services they do not come. If arrears were available here than many people would come."

Interestingly, despite the inconvenience and, for some, hardship imposed by the lack of credit early on in the new program, respondents were for the most part accepting of this fact, understanding it as a function of their unfamiliarity with the new program staff. Many respondents had not expected credit for this reason, and therefore were not surprised to be denied it during a clinic visit (though not necessarily happy), and others simply assumed it would not be available and therefore did not try. Some of the clients' and potential clients' comments included, "We have no acquaintance with them. So why would they give the methods in arrears?"; "Why would the hospital give credit to the people whom they do not know? Maybe 
they give credit to the people who live around. Why would they give us credit?"; "The [NGO clinic] does not give family planning on credit. Many women have wanted it on credit, but they have not given it. And why will they give it on credit? Do they know us?"; "The apas do not know us. So how can we make demands on them?" Although these women's comments convey an apparent understanding and acceptance of the lack of credit offered to them, it should be kept in mind that, as described above, issues around requesting payment can be very sensitive, and women who have been denied credit may in fact feel personally insulted by the implication that they are not trustworthy. Women were not understanding the absence of credit as official policy, uniformly applied to all, but rather as a function of their individual standing with the clinic providers, so their justifications may in part belie stronger feelings of entitlement. In fact, once women perceived that they were known by the providers they seemed to feel very entitled to receive credit,

"They do give credit (at NGO clinics). I have a card and I know people. Do they have any other choice but giving the methods to me on credit?"

The economic necessity of receiving services on credit in these sites was clearly mixed. For some the service was primarily a convenience and its absence would not have measurably altered their access to health care. For example, one woman experienced benefits from having access to credit, but it was not essential:

"If I am given on credit then it will be good for me. Suppose I don't have money. Then I have to borrow money from different people and procure the method. If I am given it on credit then I need not do this...But whether they give it on credit or not, I get it nearby my house. And this is convenient. Earlier I had to walk such a long distance and pay five taka to take injection. Now I have to pay five taka nearby."

For some, particularly in the earlier stages of the program when many women did not yet know that money was needed to pay for services, availability of credit helped some women avoid the inconvenience (or embarrassment) of having to go back home from the clinic to collect cash which they had not known they needed. The issue was therefore not that they did not have the money at home or at their disposal, but rather that it was just not "in hand" during their clinic visit. One of the depot holders confirmed that many "rich" women would sometimes take services on credit for this reason.

However, for many women the need for credit is not just a matter of convenience, but rather a function of poverty and gender-related constraints in access to cash. For example, one women who was very dissatisfied when she was denied credit at the NGO clinic complained,

"From then on I will never go there for medicine. We have to go to the private doctor, as we are working class people and therefore do not always possess taka. Our husbands spend all of our earnings. They cannot give taka to our hands. So if we are attacked with illness when we do not possess taka then of course we will not go there, as cash payment is required. But we can get credit from the private doctor any time." 
However, this woman also expected that her relationship with the providers, and therefore her potential access to credit, would improve over time. She said that later their "behavior" had improved and so she had gone back for injectables and was becoming more familiar with the staff.

"Now they know me so soon they will give [credit]. I understand that as they did not know me before they did not give me credit. Now they will. For this reason I will go to [the NGO clinic] again."

Credit is often an important consideration in deciding where to get treatment. Indeed, some women will even ultimately spend more in order to pay on credit by, for example, going to a private, more expensive practitioner with whom they have a personal relationship.

It is clear that while the NGOs have by now developed procedures for providing credit and do convey to the clients that they expect repayment (at times excessively, in the eyes of some respondents), credit provision is also a way in which staff informally facilitate discounts for particularly needy clients. On the part of the clients, with the exception of a very few who intentionally avoided repaying their debts because they objected to the charges, women take their responsibilities for repayment very seriously. The majority of women do intend to pay back their loans and only fail to do so because of serious chronic shortfalls in cash. One woman commented rather indignantly that the DH never had to demand repayment from her because of course she would clear her debts, "Don't I have my own sense? I am taking something on credit - don't I have to repay it?" When women cannot repay they often feel quite ashamed. For example, a woman we interviewed stopped going to the DH for pills and instead traveled farther to the FWC when she was short on money because she was ashamed to collect from the DH as long as she had outstanding debts. On several occasions the DH came to her house to collect money and she was very embarrassed that she could not pay. Another woman who clearly had problems accessing her household's resources elected to stop taking methods on credit during the doorstep program because she had outstanding debts and felt bad, even though the depot holder did not pressure her. Instead she sent her husband to the market for pills since then he would have to pay for them himself.

Under the new system, depot holders are often relied upon to collect debts - both by receiving payment from women later who bring it to the DH unsolicited, or by seeking out the women and requesting money. At a clinic, for example, a woman who cannot pay the full amount or requests credit will be told to pay what she can and then submit the balance to the depot holder at a later time. Whether the woman is sufficiently "familiar" and trustworthy is therefore often determined by the depot holder who by default becomes responsible for her debt. As noted above, depot holders have only reduced financial incentives to assume such responsibility under the new program and therefore are not inclined to facilitate credit for women they do not deem worthy of credit. One woman wanted a strip of pills from the depot holder on credit but the DH refused despite her repeated requests, arguing, "I would have to run after you for the money later." This DH reported that women who create problems in paying their debts the first time are generally not allowed to take services on credit again. She personally only gives credit to those people from whom she thinks she can collect the money. This reliance on the discretion and efforts of the depot holders to facilitate credit is not only burdensome for the depot holders, who already 
have substantial responsibilities and yet are not considered full staff members, but may also inadvertently deprive credit (and unofficial subsidies) to the women who need it most.

\section{CONTINUITY AND CHANGE - LEGACIES OF AND DEPARTURES FROM THE PREVIOUS PROGRAM MODEL}

The NGOs' efforts to introduce new services delivery approaches are occurring in the context of entrenched practices and expectations shaped by the "service delivery culture" of the longstanding national family planning program. As described above, one of the key legacies of that program has been expectations regarding the government's responsibility to provide certain types of services at nominal cost, if not free, especially for the poor. As our findings demonstrate, these expectations linger and have influenced how the NGOs' services strategies, particularly around payment, are perceived by clients and potential clients. NGO service providers have also inherited ideas about the paternalistic role of programs and providers in family planning and this, too, can be reflected in their work. For example, one NGO provider tried to reassure a woman who stopped taking pills because she was told by people in her community that they would make her infertile, and in doing so perpetuated notions that the government (and the NGO) is responsible for individuals' contraceptive behavior and outcomes:

"What do they (the people who said pills would make her infertile) know? We are the people who help for family planning.... The government does this for you. Can the government do what is wrong?"

One of the most pronounced legacies inherited by the NGOs relates to the predominant focus of the old program on family planning and recruitment of contraceptive "acceptors" at the expense of quality of care. This emphasis meant that under the old service delivery model comprehensive information, contraceptive choice, and family planning follow-up were sometimes compromised. For example, one of the former family planning workers in the rural research sites (who was not retained in the new program) was describing her work during the doorstep program and said she purposely did not tell clients about side effects:

"I did not tell all of them in the same way (about the possible side effects). Because if I told them, many women would not take this injection. Besides this, our office gave us a target to increase the injection clients. So for this reason we did not always tell them about the problems."

That this historic program emphasis shapes contemporary client expectations is evident in numerous ways. It explains, for example, why the respondent described above who was not pressured to accept a contraceptive method by the NGO staff noticed that and considered it praiseworthy. It also explains the persistent association between the NGO programs and family planning and, more specifically, the intention to promote method use. When one of our researchers introduced herself to a woman and asked if she knew of the NGO clinic, the woman, thinking that the researcher was with the NGO, immediately replied that there is no use talking to her because she does not use any family planning method. Her reaction is telling in that she 
clearly associated the NGO with family planning despite the fact that she had been to the clinic months before for a non-family planning matter.

One service provider reported that there had been three IUD acceptors one month--two came "by motivation" and the third came on her own. She said the first two women had refused to pay, since they had agreed to take the method at the encouragement of the provider they felt they should not have to. The third woman did pay, but not the full amount that was asked. Thus, it appears that the continuing "motivation" efforts of the NGOs are reinforcing the idea that the NGOs have reasons of their own for wanting women to use contraceptives, beyond the interests of the women themselves. The idea that women should not have to pay for treatment of contraceptive side effects is also consistent with the notion that users of family planning are doing what is being asked of them and therefore should not have to make sacrifices to do it. Yet the underlying premise of the new NGO program is that people will seek out reproductive health services for themselves, and that they will pay for the services, if they are accessible and of high quality.

The historic emphasis on recruitment of contraceptive "acceptors" has lingering effects on providers as well as clients. We interviewed depot holders who made it clear they thought that efforts to increase contraceptive use should not come at the expense of service quality or go against the wishes of the client. We also did not encounter any examples of women reporting being pressured to accept a method by NGO staff. But the continued emphasis on methodspecific (rather than client-driven) motivation is apparent in many ways. One NGO service provider attributed an increase in clinical method use under the new program to the fact that everyone is being encouraged to adopt clinical methods by the clinic staff as well as the government worker. Other respondents described being encouraged to take an IUD or ligation by the depot holder. They said she (the DH) tells people they are good methods and is happy if people use them. (Meanwhile they hear from those who use those methods that it is better to take pills or injectables). They reported that the DH is not forceful in her efforts (and these women did seem very comfortable declining her offer), but she "tells everyone to take these methods." In light of the compelling evidence of strong demand for family planning (and in light of responses like these), it seems clear that method-specific motivational techniques are unnecessary and may even be counterproductive. What is needed is good information and access, not persuasion.

We encountered in the research many examples of staff of the new NGO program overcoming the legacies of the past and introducing service approaches that were both positive from an objective quality of care standpoint, and also appreciated by clients. For example, many women we interviewed reported that they had been informed in advance of possible side effects before they took injectables for the first time. Another woman reported that she was told of possible disadvantages of the IUD in advance and told to come to the clinic if she had problems. When she had subsequent "excessive bleeding" she did not think it too bothersome and when asked by the researcher why she found it tolerable she said that, as she had been told by the paramedics in advance that this might happen, she was not concerned about it.

Women also appear to be getting more satisfactory assistance with management of side effects under the new program. As described above, many women were unhappy with the limited advice 
they received from the family planning workers that they often felt was inadequate and/or unrealistic (i.e., advising them to change their diet to include more "rich" foods). One of the new DHs reported that if someone informs her about her side effects, she tells the woman to go to the satellite clinic and to discuss it with the paramedics there since she herself does not know the solution. She is concerned that if she provides bad advice and the situation worsens then the patient would hold her responsible. Other women we interviewed reported that providers had been responsive to their complaints of side effects and were supportive if they wanted to change methods. For example, one woman was experiencing what she considered unacceptable side effects related to an IUD and happily reported that the paramedics agreed with her that the method was not suitable for her and removed it "without any hesitation."

Although the NGO staff seem to be more proactive in providing information to clients than in the past, it is often uneven and in many ways still on a need to know basis as determined by the staff. Providers seem to often assume, paternalistically and erroneously, that their clients will not understand or make the "correct" choices if they are given full information. For example, when asked if they make people in the community understand that they are not government workers, one depot holder said that they tell only those who ask them, but not willingly to everybody. In answer to the query why they did not tell them, she said that village people were poor and illiterate and could not understand what the clinic workers had to say.

Another woman asked a depot holder directly where they come from and was told that they were affiliated with the THC. In this case the DH probably just thought she was being helpful by naming a provider the client was mostly likely familiar with, but in the end this perpetuated confusion unnecessarily. Similarly, staff often seemed to improvise with explanations about the services charges in ways that may only have exacerbated confusion and mistrust. One woman bargained with the paramedics at the satellite clinic, asking them why they are taking money if the government sent them and is giving them a salary. Rather than explaining that they are not from the government, the paramedics said they should be paid because they have come from very far away and tried to rationalize with her, arguing that if she went to the government clinic instead she would have to travel far and pay money for the rickshaw anyway. Other women were similarly given excuses for why the satellite providers charged--like needing money for tea and snacks since they have to travel--rather than a full explanation. Often to get more complete or satisfying information women have to be very proactive and persistent. And as our research has demonstrated, it is still the case that many women are inhibited from seeking information, especially if they are not familiar with the providers. Yet the research also indicates that with more, complete information up front women are usually more satisfied and unnecessary confusion (as well as suspicion) is avoided. 


\section{CONCLUSION}

The findings presented here should be interpreted in light of several considerations. First, the phenomena that we are studying - the new program model and peoples' reactions to it - are still rapidly evolving; new services and strategies are still being introduced and utilization patterns are still in flux. Second, the data presented here come from only two sites. Although we selected sites in collaboration with Pathfinder that were believed to be fairly typical of the rural areas in which the new program is being implemented, barriers to service utilization based on gender, geographic constraints, inadequate information, and other factors may be more severe elsewhere. It is also possible that the impact of the program transition was greater in areas where the withdrawal of door-to-door services was more abrupt and complete than in these sites. Third, it is important to note that this study is not intended to serve as an evaluation of the effectiveness of the new program strategies. The research documents the perspectives and responses of users, communities, and providers as the new service delivery model is introduced, and tries to understand these reactions in light of the socioeconomic, cultural, and historical context. To derive useful policy lessons about the management and impact of the program transition, the findings presented here should be considered along with other ongoing efforts by USAID and the NGO partners to describe the effects of the new program in more quantitative terms.

Bangladesh is one of many countries struggling to narrow the gap between policy and implementation of the expanded approach to reproductive health agreed to at the International Conference on Population and Development (ICPD) (Hardee, et al 1999). Many of the ICPD goals are embodied in the government's Health and Population Sector Strategy (GOB 1997). In the Sector Strategy the Bangladesh government has laid out an agenda for change that is in some ways quite radical, and the USAID-supported NGOs are moving ahead to implement these changes. In doing this the NGOs face problems shared by health programs worldwide who are pursuing reform policies. So far there are few if any documented health sector strategies that have succeeded on a large scale to simultaneously expand access for the poor, improve the quality of services, and increase cost recovery and sustainability. Given the difficulty of the task, the progress that the NGOs have made in a relatively short period of time is impressive.

The new NGO program is important as a test case of the new strategies because of both the nature of the changes made, and the speed with which they have been introduced. As noted in this report, many of the assumptions behind the changes had not been systematically proven, and some were controversial - for example, the assumption that demand for family planning is not too "fragile" to withstand the withdrawal of home-supply and that norms related to purdah will not prevent women from utilizing services outside the home. Our findings in the rural areas confirm quite clearly, however, that men and women are strongly committed to fertility control, and women are for the most part no longer socially constrained from visiting clinics - at least not in our research sites. The NGOs have been able to capitalize on these changing norms, but they are also developing strategies to address the exceptions that persist. It will be important that NGOs continue to provide information and support so that the strong existing demand for services and the loosening restrictions on women's mobility translate into effective and satisfactory service utilization. The NGOs' outreach efforts to men are one promising vehicle for promoting messages about men's important roles in ensuring access to family planning, clinical services, and information, and should be strengthened. 
Through various ongoing outreach strategies and sustained information dissemination, the NGOs should be able to ensure access to the new services for most people who need them, with the exception, perhaps, of those for whom payment issues are perceived to be problematic. We have found that most clients think the current charges are reasonable, even though some have problems paying, but there is the danger that potential clients are not seeking out the services based on a perception that the cost is prohibitive. The NGOs are clearly aware of and concerned about this possibility and the staff is trying to identify individuals or groups who may be most in need yet not accessing services adequately. One important component of their efforts, supported by our findings, could be a transparent and clearly structured system of need-based subsidies. A more formalized system could also be developed for extending credit to women whose families can and are willing to pay but who do not always have access to cash. Such a system should be available to all who need it, not only those with "familiarity", but should also not depend too heavily on the oversight of depot holders. Simply relying on the poor to decipher ambiguous messages about the availability of subsidies and/or be assertive in pursuing their needs for credit or discounts will certainly not be sufficient to achieve the NGOs' goal of ensuring access for all.

Our findings also indicate that the NGOs have largely succeeded in understanding and incorporating many aspects of quality that are important to clients. People appreciate access to more comprehensive, higher quality family planning services, the improved physical environment of the clinics and, especially, the interpersonal aspects of the new NGO services. The findings also indicate, however, that there are other, complex aspects of quality that the NGOs are still struggling with, mostly stemming from confusion about the role of NGO services vis-à-vis other providers. These relate to charging for services and provision of a level of health care that is understood to be more than family planning, but less than comprehensive "treatment." Again, these problems may resolve themselves over time and with better information. For example, the NGOs need to clearly distinguish themselves from the government and to explain why fees are collected and how this income is used. Clients clearly value quality and convenience, and in many cases are willing to pay more for these benefits, but better communication is still needed to explain, clearly and proactively, how the new services are set up and to dispel expectations that developed in relation to the previous family planning program model. Similarly, clear explanations to community members about the specific service niche of the NGO clinics and the function of referrals should help dispel confusion and also resonate with clients' experiences with traditional health systems.

Finally, our research demonstrates that program staff and clients are indeed able to adapt to the new ways of thinking mandated by the new service delivery model. This is supported, for example, by the very positive finding that rich and poor are treated alike, and with respect, in the clinics. Other evidence, however, suggests the persistence of norms and expectations from the past. As our findings demonstrate, the legacy of the previous program model and the prevailing service delivery norms affect the new program strategies in several ways. As a result, it will be necessary to come to terms with prevailing ideas about entitlements, and about paying for services. It will also be necessary to overcome the legacies of the historic disproportionate emphasis on increasing contraceptive use. The still widespread perception that family planning services are offered as part of a national fertility reduction agenda presents a challenge to the NGOs as they try to implement a sustainable, client-centered essential services model. This 
perception can influence clients' attitudes regarding the legitimacy of charges for family planning methods and services, and also foster mistrust between clients and providers. Ongoing emphasis on method-specific motivation by providers is therefore not only unnecessary, but also possibly counterproductive. Donors and implementing agencies need to exercise caution as they try to expand the range of family planning methods available, to avoid the interpretation by providers that clients should be recruited to use these methods (Diaz et al., 1999; Simmons et al., 1997).

Reconciling the new program with these legacies will require improved coordination between NGOs and government, additional measures to "mainstream" the essential principles of the government's Health and Population Sector Strategy within both government and NGO service delivery systems, and continued emphasis on communication between service providers and users. The new service delivery policies need to be translated and conveyed in ways that make them more comprehensible to the communities that the NGO clinics are meant to serve, and increase their perceived legitimacy.

In conclusion, our findings from the rural sites (as in the urban sites) strongly support the policy changes reflected in the government's integrated, clinic-focused approach and the new USAID NGO program. Clients and communities are responding favorably to many aspects of the new model, and there do not seem to be intractable social barriers to service utilization. Clear and timely information would have made the transition from door-to-door services easier for many women, but once they were aware of the new system most of them adapted quickly. Many of the issues the NGOs continue to struggle with as they introduce new services and program strategies will likely resolve themselves as a function of time, particularly if the NGOs are able to sustain the level of service quality achieved so far. Indeed, over the course of implementing the transition to the new service delivery model, improvements related to access and quality have increased dramatically over time. The depot holders deployed by the NGOs have been very instrumental in smoothing the transition to the new program and they remain an important resource for clients and providers alike. However, it is important that they are not overburdened with responsibilities they do not have the time or skills (or incentives) to manage. The depot holders are for the most part clearly committed to their clients, but their work is also informed by their assessments of the "cost-benefit" tradeoffs they face. Rewarding the depot holders for their efforts to promote quality and overall service utilization, rather than increasing family planning users or recovering clients' debt, will help to both encourage them to do their work and reduce the risk of distorted incentives.

A number of the challenges the NGOs face, particularly related to cost recovery, are a function of expectations and norms from the past, and of incongruences between government and NGO pricing policies. As the NGOs, and the Bangladesh government, proceed with implementation of the integrated, essential health services model, additional strategies will be needed to erode the paternalistic service delivery culture that evolved in the context of a vertical family planning program. In pioneering the difficult task of transitioning from door-to-door family planning to clinic-based essential services, the NGOs' have demonstrated both the potential of the new program strategies and the challenges inherent in such a major reorientation. As the government moves forward with its own transition, much can be learned from the NGOs' experiences in dealing with the complex challenges of pursuing simultaneously goals of quality, access, integrated service delivery, and cost-recovery. 


\section{REFERENCES}

Alauddin, Mohammad. 1999. "Revolving Fund for Medicines: Pathfinder Success in Bangladesh. Prajanma. Dhaka, Bangladesh.

Diaz, Margarita et al. 1999. "Expanding Contraceptive Choice: Findings from Brazil." Studies in Family Planning 30:1.

Government of the People's Republic of Bangladesh. 1997. "Health and Population Sector Strategy." Ministry of Health and Family Welfare, Government of the People's Republic of Bangladesh.

Government of the People's Republic of Bangladesh. 1996a. "Productivity and Costs for Family Planning Service Delivery in Bangladesh: The Government Program.” Technical Report, Population Development and Evaluation Unit, IME-Division. Ministry of Planning, Government of the People's Republic of Bangladesh.

Government of the People's Republic of Bangladesh. 1996b. "Productivity and Costs for Family Planning Service Delivery in Bangladesh: The NGO Program.” Technical Report, Population Development and Evaluation Unit, IME-Division. Ministry of Planning, Government of the People's Republic of Bangladesh.

Hardee Karen, Kokila Agarwal, Nancy Lute, Ellen Wilson, Margaret Pendzich, Marguerite Farrell, and Harry Cross, 1999. "Reproductive Health Policies and Programs in Eight Countries: Progress Since Cairo.” International Family Planning Perspectives. 25:?.

Hossain Mian Bazle and James Phillips, 1996." The Impact of Outreach on the Continuity of Contraceptive Use in Rural Bangladesh." Studies in Family Planning. 27:2.

Hossain Mian Bazle, Barkat-e-Khuda, and James Phillips, 1995. "The Effects of Outreach Worker Visits on Perceived Quality of Care in Two Rural Areas of Bangladesh.” Paper presented at the Annual Meetings of the Population Association of America, San Francisco, CA, April 6- 8, 1995.

Jamil Kanta, Kim Streatfield and Sarah Salway. 1996. "Modes of Family Planning Service Delivery in the Slums of Dhaka: Effects of Contraceptive Use." Working Paper No. 16., MCHFP Extension Project (Urban), Health and Population Extension Division. Dhaka, Bangladesh: ICDDR,B.

JSI Research and Training Institute. 1997. "Urban Service Delivery Design and Result Package." Arlington, VA: JSI Research and Training Institute.

JSI Urban Family Health Partnership. 1998. Annual Report 1997/98. Dhaka, Bangladesh.

JSI Urban Family Health Partnership. 1999. Annual Report 1998/99. Dhaka, Bangladesh. 
Phillips James, Mian Bazle Hossain, and Mary Arends-Kuenning. 1996. "The Long-term Demographic Role of Community-based Family Planning in Rural Bangladesh." Studies in Family Planning. 27:4.

Pinkham Fred, et al. 1995. "The Bangladesh Family Planning and Health Services Project, Strategic Options Report." POPTECH Report No. 95-040, prepared for USAID. Arlington, VA: Population Technical Assistance Project.

Schuler, Sidney Ruth, Amy Cullum, and Sharif Shamshir. 1997. "Reorienting Community-based Family Planning Services in Bangladesh: Problems and Prospects.” JSI Working Paper No. 11.

Schuler, Sidney Ruth, Syed M Hashemi, Amy Cullum, and Mirza Hassan. 1996. "The Advent of Family Planning as a Social Norm in Bangladesh." Reproductive Health Matters. Number 7.

Schuler, Sidney Ruth, Syed M Hashemi, and Ann Hendrix Jenkins. 1995. "Bangladesh's Family Planning Success Story: A Gender Perspective." International Family Planning Perspectives. $21: 4$.

Simmons, Ruth, et. al. 1997. "The Strategic Approach to Contraceptive Introduction." Studies in Family Planning 28:2.

Simmons, Ruth, Laila Baqee, Michael Koenig, and James Phillips. 1988. "Beyond Supply: The Importance of Female Family Planning Workers in Rural Bangladesh." Studies in Family Planning 19:1.

US Agency for International Development. 1996a. "Urban and Rural Service Delivery Components of the New Initiatives in Population and Health (NIPH) Project." RFAUSAID/Bangladesh-96-P-001. Washington, DC, March, 1996.

US Agency for International Development. 1996b. "Quality Improvement Component of the New Initiatives in Population and Health (NIPH) Project.” RFA-USAID/Bangladesh-96-P-002. Washington, DC, March, 1996.

US Agency for International Development. 1996c. "National Integrated Population and Health Program (NIPH) Design Workshop Report.” Dhaka, Bangladesh: USAID. 